\title{
The institutionalization of regions: a theoretical framework for understanding the emergence of regions and the constitution of regional identity
}

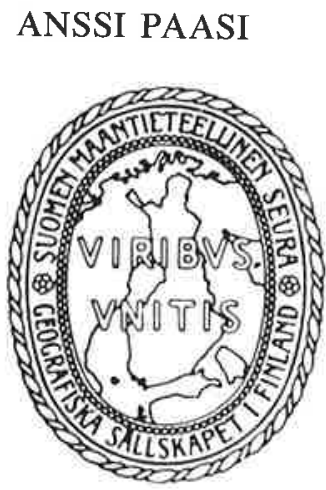

\begin{abstract}
Paasi, Anssi (1986). The institutionalization of regions: a theoretical framework for understanding the emergence of regions and the constitution of regional identity. Fennia 164: 1, pp. 105-146. Helsinki. ISSN 0015-0010.
\end{abstract}

The aim of the present study is to examine the differences between the classical categories of geographical thought, region and place, and their relation to the societal context and the day-to-day practices of individuals. After analysing the traditional definitions of the concepts, an interpretation of the concept of region as a human and social category is put forward. The region is comprehended as a historically continuous process whose institutionalization consists of four stages: the assumption of territorial shape, the formation of conceptual (symbolic) shape, the formation of institutional shape and establishment as an entity in the regional system and social consciousness of the society. As regards the concrete regions in a society, the order of these stages can vary. Institutionalization of a region is a process during which some specific level of the spatial structure becomes an established entity which is identified in different spheres of social action and consciousness and which is continually reproduced in individual and institutional practices (e.g. economic, political, legal, educational, cultural, etc.). The meanings of the concept 'regional identity' are also discussed as an expression of the dimensions of an institutionalized region. The nature of regional communities, regional consciousness and images of regions is discussed using the framework of the institutionalization of regions as a background.

Anssi Paasi, Department of Geography, University of Joensuu, P.O.Box 111, SF-80101 Joensuu, Finland. MS. received 2nd May, 1986 (revised 31st August, 1986).

The problem and its background ........ 106

A revival of regional geography? ...... 106

Aims of the present study ........... 109

Exploring the boundaries between region and

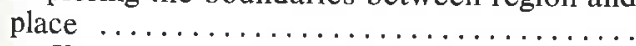

Human experience as a basis for the distinction $\ldots \ldots \ldots \ldots \ldots \ldots \ldots \ldots$

Region and place in the present study ...

The concept of region in geographical tradition

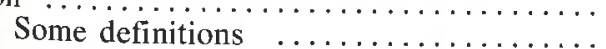

The region as a community ............

Institutionalization of regions: re-interpreting the concept

The region as a human and social category

Institutionalization of regions $\ldots \ldots \ldots \ldots$

Structures of expectations $\ldots \ldots \ldots \ldots$.

Assumption of territorial awareness and shape
Development of conceptual (symbolic) shape $\ldots \ldots \ldots \ldots \ldots \ldots \ldots \ldots \ldots . \ldots 125$

Development of the sphere of institutions Production and consumption of space Excursion: the Finnish case ....... 111 The region as an established part of a regional system and regional conscious-

A framework for conceptualizing "regional identity" ........................

Regional identity of inhabitants ....... On the nature of regional communities Identity of a region $. . . \ldots \ldots \ldots . . .$.

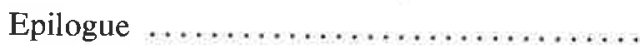

Notes

Acknowledgements

References 


\section{The problem and its background}

\section{A revival of regional geography?}

Presumably the scholars of all scientific disciplines operate with some basic concepts that are essential as regards the constitution, intellectual history and continual reproduction of the intellectual basis of the discipline in question. It is common for the content and definitions of the concepts to vary in time in the course of the development of general philosophical and methodological trends in scientific thought and in relation to the social context in which the research work occurs. These concepts are of particular importance for the identity of the subject within the broad field of academic disciplines. As to the relationship between human sciences and society, these concepts have a twofold role. Firstly, from the perspective of the discipline concerned, they are continually reproducing and directing approaches aimed at analysing theoretically and/or empirically given spheres of the society and social practice. Secondly, as regards the society, this work and its applications are usually significant not only in providing the identity for a subject among other disciplines, but also in building up the world view of the citizens (intellectual reproduction) and - from the viewpoint of different interests in knowledge and their social constitution - in planning, policy-making and other social practices (and forms of social control) necessary for social reproduction.

The concept of region has been, and still is, one of the basic categories of geographical thought, together with others such as space, place and their 'derivatives' distance, location and accessibility. As regards the intellectual traditions of geographical thought in different countries, as a symbol of the identity of the subject, the concept of region appears by traditon to be an internal product of geographical discourse, the relationship between the discipline and social practice having later modified the interpretations connected with it. The concept of region belongs by tradition to the conceptual apparatus of regional geography, which has dominated geographical thought up to $1950 \mathrm{~s}$. Although its concentration on the description and interpretation of regions of different size has caused it to lose its central role in academic geographical work and the intellectual reproduction of geographers, regional geography is still one of the fundamental approaches in schools, an aspect which is crucial for the constitution of our outlook on world as a part of social reproduction. The concepts of region developed by academic geographers have usually been static, although the intellectual history of the discipline contains some exceptions, and the concept of region implicit in school geography is also static, the regions concerned usually being portrayed by means of cross-sections in time.

Regional geography has at times been comprehended as the "crown of the discipline of geography" and in this respect it is encouraging that during the last few years a revival has taken place in the literature dealing with its theoretical principles. Humanistically oriented geographers have been deliberating the nature of regional geography and regional description (Buttimer 1979, Jeans 1979), and a more interdisciplinary perspective has been provided by geographers acquainted with recent developments within the social sciences (Pred 1981b, 1984a, Thrift 1983, Lee 1985). The latter have made significant contributions as regards the social constitution of regional geography. The works produced within modern sociology and social philosophy have also been an essential source of inspiration and justification for other geographers, too (see Carlstein 1981, Gregory 1981b, 1982a, Gregory \& Urry 1985). Especially fruitful ideas have arisen from the theorists of the structuration school, who have, in spite of certain similarities in their basic ideas, shown wide variation in focus and concepts (see Bourdieu 1977, 1985a, Giddens 1976, 1979, 1981, 1984, Habermas 1979). And it is not only geographers that have benefited from their discourse on social theory, for Anthony Giddens in particular has found some works of geographers important regarding the basic premises of the structuration theory. To put it briefly, the latter aims at conceptualizing the relation between human action and social structure, a fundamental point of departure being that the structural properties of social systems are both the medium and the outcome of the practices that constitute those systems (Giddens 1981: 27). This postulate is called duality of structure. Structure consists of different rules and resources that are recursively implicated in the reproduction of social systems. The structura- 
tion process refers to the structuring of social relations in time and space, and it is essential to note that social reproduction (in time and space-specific situations) is an ongoing process through which individuals are socialized as members of societies. In the reproduction of social life, acting individuals more or less routinely draw upon interpretative schemes, resources and norms made available by existing structures of signification, domination and legitimation - and thus also reconstitute the structures of society (Gregory 1981b).

As to new approaches on regional geography, Allan Pred (see also Thrift 1983, Lee 1985) in particular constructs his framework by enlarging on the ideas of the modern theory of structuration and concepts of time-geography developed especially by Torsten Hägerstrand (1970, 1973, 1978). Pred's perspective is interesting, inasmuch as he aspires to develop a theoretical foundation for a new "place-centred or regional geography". Pred (1984, 1985a) criticizes previous geographical concepts of place and region on the grounds that, in his opinion, places and regions have until recently normally been treated in ways that underline the role of certain measurable or visible attributes of an area during some arbitrary period of observation. According to Pred these areas are ultimately portrayed as "frozen scenes for human activity". Pred also criticizes the concept of place developed and used by humanistically oriented geographers during the $1970 \mathrm{~s}$, maintaining that in essence these geographers too have conceived of place as an inert, experienced scene. One of Pred's basic ideas is to conceptualize the place as a process whereby "the reproduction of social and cultural forms, the formation of biographies and the transformation of nature ceaselessly become one another at the same time that time-space specific activities and power-relations ceaselessly become one another"' (Pred 1984a: 282).

Guelke (1985) has recently stated in his comment on Pred's text that in principle Pred is analysing a well-known geographical problem that has been present in the works of historical geographers for a long time. Smith (1965), for instance, expounded the historical point of departure for studying places as follows: "As long as geographers are concerned with the study of places and what they are like, how they differ from each other, and how their parts are interrelated, they will want to know how these places came to be what they are and what they were like in the past' ( 1 ; see notes). It is to be noted, however that according to a real processual framework there does not exist any $a$ historical geography (cf. Gregory 1982c: 17). As regards methodological discussions, some geographers have put stress on the dynamic character of places. Lukermann (1964), for instance, poses that "the character of the places of the earth is always emergent and becoming". From the perspective of time-geography Parkes and Thrift (1980: 23) note an absence of substantial statements as to where place comes from, or what makes a place more than a grouping of material artefacts.

What superficially distinguishes Pred's ideas from the previous ones is his employment of the conceptual apparatus developed by the theorists of 'structuration', connecting it with the time-geography framework, which is an interesting perspective and contribution as regards the methodological premises of (historical) geography. The critical debate between Guelke (1985) and Pred (1985a) indicates, however, that the essential distinction between the 'old' historical geography and the approach put forward by geographers inspired by social theory goes in fact very much deeper than the level of concepts. Pred's, Thrift's, Gregory's etc. explicit connection with modern social theory implies a more fundamental movement from - to use the concepts of Jürgen Habermas - technical interest in knowledge to practical and finally emancipatory one, from solely collecting information on the facts of the objective world (to exploit it as a technical apparatus in the control of nature and society), to understanding cultures and finally to determining the social and psychological "fetters" which confine society and in this way to mastery over them and the releasing of people from their control. Thus the central concern in a "structurationist" framework lies in the direction of analysing the power relations that emerge from individual and institutional practices and other "invisible" realities instead of the purely material phenomena that have traditionally fascinated the minds of regional geographers.

One point should be noted with regard to the conceptual basis of regional geography, however. Although Pred (1984a) states that he is developing a theoretical foundation for 
a new regional geography, it appears to be that region, its basic concept, is partly taken as given in his framework. Pred emphasizes the importance of time-space specific activities and the dynamic role of places (cf. Giddens 1979), but does not set forth any explicit definition of the concept of region and does not make any conceptual distinction between region and place. Both region and place are reduced in the same manner to individual and institutional practices. Although Pred (1984a) does not explicitly deliberate upon the role of the concept of community, which presumably would promote a comprehension of the constitution of places and regions from the human perspective (see, however, Pred 1983), these problems are implicit in his framework inasmuch as he notes that the ideas of the Vidalian tradition, for example, with its emphasis on local practical life and its conceptualization of genre de vie are of importance to his ideas (see also Pred 1981b: 247-248). Pred (1984a: 281) states that structuration processes may occur simultaneously at multiple spatial levels, interpenetrating with one another through the practices associated with mediating institutions or individuals. This statement also implies a hierarchical role for the socio-spatial structure, which is of crucial significance for understanding the differences between these practices at different regional levels.

For Thrift (1983) a region is "the 'actively passive' meeting place of social structure and human agency, substantive enough to be the generator and conductor of structure, but still intimate enough to ensure that the 'creature like aspects' of human beings are not lost'. $\mathrm{He}$ looks on the region as a kind of interaction structure (an idea also implicitly present in the theory of Pred, 1984a) which is made up of a number of different but connected settings for interaction. Thrift cites the word locale, coined by Giddens (1979, 1981, 1984), to carry this idea. Locale refers to the use of space to provide a setting for interaction, and is not bound to any specific regional level: "A locale does not have to be local" (Thrift 1983). Instead, Giddens (1984: 118) stresses that it may range from a room in a house, a street corner, the shop floor of a factory, a town or a city to the territorially demarcated areas occupied by nation-states. Thus the setting for interaction can vary a lot in time and space. Thrift also makes a conceptual distinction between region and place but does not discuss the distinction in detail. Although he analyses the constitution of the structures of regions, it appears to be that idea of region is reduced in his proposal to a frame in which "social activity (in any region) takes place as a continuous discourse, rooted in a staggered series of shared material-situations that constantly arise out of one another in a dialectically linked distribution of opportunity and constraint, presence and absence'. Thrift nevertheless emphasizes, that "a region is lived through, not in", a statement clearly indicating a kind of "community" perspective which refers to the relationship between the region and its inhabitants.

Ever since the classic works of Durkheim and Tönnies, social scientists have assessed the consequences of the division of labour in the constitution of the structures of society and social consciousness. It is quite normal to consider that the role and content of the social reproduction and socialization process, the perpetual process through which people become and are citizens of communities and finally nation-states, changes radically in the course of the development of a society. A common conclusion is that the traditionally fundamental face-to-face relations will lose their role as the only crucial form of socialization in modern society, and that the relationship between "us" and "them" in communities will change a lot, so that traditional local communities of high-presence availability, where inhabitants know each other and work together, will be progressively replaced by abstract, differently symbolized reference groups whose members people are instilled in the course of the socialization process. One's "Lifeworld" (Lebenswelt) and its symbolic structures become threatened when the system and the rationality of economy and bureaucracy colonize the sphere of cultural meanings which has by tradition been an essential part of social identity (and social reproduction). The division of labour enhances the interdependence of the parts that constitute the system and accentuates the role of different forms of capital (cultural, social, economic, etc.) and power (Bourdieu 1977, 1985a, Habermas 1981, Giddens 1979).

In modern societies the hierarchical nature of spatial reality manifests itself powerfully in the reproduction of the features and contents of spatial consciousness, for instance. 
The institutions of societies (e.g. symbolic orders/modes of discourse, political institutions, economic institutions, law/modes of sanction, as presented by Giddens 1979: 107) are specialized in connection with the spatial structure so that they form dynamic, hierarchically organized structures around the human beings, in spite of the fact that these institutions are constituted and reproduced in human practice, and ultimately in the day-today life of individuals. Socialization, during which the individuals become members of society, is not a passive process in which the society stamps its mark upon single individuals, but instead individuals actively participate in the reproduction of society (see Giddens 1979). Although it is the routinized action of individuals by which the structures of society are reproduced, single individuals are not in the same position in this process. The division of labour and its spatial consequences, manifesting themselves in economic and power relations, define the role of single individuals in creating, maintaining and reproducing the structures of society and hence also the symbolic dimensions of space. There are undoubtedly always some people and groups in all societies (nation-states) that have specialized in producing and reproducing the spatial dimensions of individual and collective consciousness as politicians, bureaucrats, journalists, etc. Nevertheless, the role of individuals in this respect should not be overemphasized. As noted by Thrift (1983: 30), it is obvious that ordinary people do not spend their whole time reflecting upon their social situation and how to change it (or how to maintain it unchanged!). Moreover, it is apparent that the effects of the sphere of institutions controlling the actions of men are reproduced partially unconsciously in the routines of everyday life, i.e. they are taken for granted.

Presumably it is to some degree reasonable to accept what Berger and Luckmann (1976: 77-78) write about the relationship between individuals and institutions: "The individuals's biography is apprehended as an episode located within the objective history of the society. The institutions, as historical and objective facticities, confront the individual as undeniable facts. The institutions are there, external to him, persistent in their reality, whether he likes it or not. He cannot wish them away. They resist his attempts to change or evade him. They have coercive power over him, both in themselves, by the sheer force of their facticity, and through the control mechanisms that are usually attached to the most important of them. The objective reality of institutions is not diminished if the individual does not understand their purpose or their mode of operation" (2). Even though the ideas put forth above presumably work with the majority of inhabitants of some specific society, it is unhelpful to distinguish the "objective" sphere (of institutions) and "subjective" sphere (of individuals) radically from each other, since the fact is that reproduction of the institutional sphere occurs through the everyday action of individuals (cf. Abrams 1982: 240-262). Individuals are not apart from the social system under which they live. They simply have different positions in the reproduction of the society and its spatial organization (cf. Bourdieu 1985b). Seen from the angle of the system, these positions are normally much more significant for the reproduction process than the individuals holding them. Persons are important in reproduction as the holders of these positions, not as individuals as such. Social reproduction of the division of labour simultaneously continually reproduces the positions of elites (or other powerholders) that are crucial in the perpetual reproduction of the structures of the social system.

\section{Aims of the present study}

Geographers have adopted highly constitutive ideas concerning the structuration of the timespace relations in society from the theorists of modern sociology, and also vice versa. This orientation has been fruitful as far as the essence of regional geography is concerned, but it appears that the meanings of the basic concepts in geography, region and place, and the relations between them have not attracted the attention of geographers or been analysed profoundly to the same extent as these new perspectives have been developed in general. The present study starts out from the examination of these concepts in a framework that is based on the intellectual history and logic of geography and hence tries to deliberate what are the roles of, and the differences between, region and place in reflecting time- 
space relations in society and in man's day-today life.

The basic idea of present study, originating from the history of geography as a discipline, is the distinction between the concepts of region and place. The purpose is to indicate that this distinction is useful for understanding the role of institutional practices as mediators in the constitution of individual practices, society and time-space. The distinction between region and place in the context of concrete societics seems to offer one possibility for understanding the development and role of individual and collective spatial consciousness in societies. Besides analysing the meanings of these concepts, the purpose is to discuss the concept of region as a human and social category. The fundamental point of departure is to comprehend the region as a process which, once established, is continually reproduced and gradually transformed in individual and institutional practices. This starting point is closely related to that of Pred (1984a) who has recently discussed the place as a historically contingent process, but is more distinctly governed by an analysis of the meanings of the fundamental categories and the history of geographical thought than the processual and contextual approach set forth by Pred, Thrift, Lee and others inspired by the ideas of the theory of structuration. The latter is, nevertheless, of importance for formulating the perspective for the present study because of its emphasis on the inseparability of time, space and society. This raises several methodological challenges for geography, which has for a long time been apprehended, firstly in the spirit of methodological exceptionalism, then in the spirit of spatial separatism, as a special discipline of "space"' (cf. Sayer 1985).

The hierarchical nature of the regional system surrounding individuals is an undeniable fact in every modern society. In geography the relationship between the nation-state, its sub-areas and the everyday life environment of individuals is of importance since it reflects the continually changing role of time-space relations through which the constitution of society and consciousness occurs. A region is not just a mere stable, flat lattice or a given context in which all this occurs, but it has a crucial role in the process during which time, space and society are related (3). As for regional geography, it is important to consider what challenges this dynamic role of regions presents for the task of defining the conceptual basis of regional geography. The point of departure for the present study is that a region in regional geography cannot be regarded merely as a framework containing all those things, whether stones, sand, flowers, men and women, ideologies, etc., that regional geography usually synthesizes. Instead a region is comprehended as a concrete dynamic manifestation of social (natural, cultural, economic, political, etc.) processes that affect and are affected by changes in spatial structures over time. It is to be noted that the aim is not to attempt to propose a new type of regional geography, but instead to consider some principles for a better understanding of the emergence of regions, not as static frameworks for social relations but as concrete, dynamic manifestations of the development of a society. One important problem is explicitly connected with the concept of historical continuity, i.e. the question concerning the initiation, reproduction and transformation of regions and places. It is also hoped to find conceptual means of interpreting and understanding these developments.

After analysing the role of the concepts of region and place in geographical thought and the relations between them, an interpretation of region as a human and social category will be suggested. The purpose is to decompose the traditional geographical concept of region by employing a theoretical framework, where theory is apprehended as conceptualization (cf. Sayer 1984: 49), in order to understand the institutionalization of regions, i.e. the emergence of regions as a part of the socio-spatial structure and consciousness of society, and hence to understand the emergence of regional identity. Institutionalization of a region is a process during which some time-space specific level of spatial structure becomes an established entity which is identified in different spheres of social action and consciousness and which is continually reproduced in individual and institutional practices (cultural, legal, educational, economic, political, etc.). 


\section{Exploring the boundaries between region and place}

\section{Human experience as a basis for the distinction}

The history of geography as a discipline does not provide any plain instructions for distinguishing the concepts of place and region. Geographers do not always even make any distinction between the two concepts, as was noticed in the case of Pred's (1984a) article. This proceeds from the miscellaneous definitions of the concepts, which have often been confusing and have varied greatly with time. According to Relph (1976: 4), confusion about the meaning of the notion of place appears to arise from the fact that it is not merely a formal concept awaiting precise definition, but also a naive and variable expression of geographical experience. The same statement also holds good as regards the concept of region, although this usually seems to possess a kind of "material" body, at least as a framework for classification of its material manifestations in the world. When the regions and places are compared in terms of their areal extent, traditional definitions do not serve to clarify the distinction in any detail. The concept of place is naturally an abstraction - as are all concepts - if it is defined apart from the real context of concrete societies and their historical development. Expressly, the practices of society and finally the basis of its reproduction, the everyday life of individuals, puts life into the concept, and lends support to the distinction between place and region as far as geographical thought is concerned.

After analysing the essence of the concepts in question, May (1970: 211) ascertains that there would appear to be at least one sense in which the concept of "place" is perhaps distinguishable from that of "region", that a place appears to possess a perceptual unity that a region lacks (4). Earlier methodological deliberations also lend support to this statement (see Lukermann 1964). It should nevertheless be recognized that even in traditional definitions place is often comprehended as a materialfunctional concept. Location, for instance, has been stressed as constituting an essential aspect of the nature of place (see Lukermann 1964 , cf. Pred 1983). On the other hand, the subjective dimension of a region, the character which it is experienced as having, has also been one of the classical problems in regional geography throughout its history as an institutionalized discipline (see Paasi 1983).

The emergence of modern humanistic geography with its re-definition of the concept of place has established the subjective (experienced) and human aspects of the concept of place (it must be recognized that humanistic geographers have also laid stress on different aspects of the nature of place in detailed discussions). For the present purposes it appears to be fairly practicable to define the concept of place in a manner similar to that employed by humanistically oriented geographers, i.e. as a phenomenon that is structured in the process of one's everyday life and hence is based on the day-to-day practices of individuals. The essence of place is said to lie in a "sense of place", a largely unselfconscious feeling of belonging to one's place (see Relph 1976, Tuan 1977) (5). This humanistic view is also canonized in the definitions put forward in the Dictionary of Human Geography, where Billinge (1981: 254), after specifying a place as a portion of geographical space occupied by a person or thing, falls back on formulations that are currently common in the frameworks used by humanistic geographers. In this way place is based on the lifeworld and everyday actions of the individual. It is a perpetual, personal interpretation of the meanings emerging from time-space specific situations in one's everyday practices.

The concept of place enables one to depict the context, in which - to cite concepts coined in time-geography - the paths and projects of the everyday life of individuals are realized. The concept of path refers to the fact that the existence of individuals (and all other entities) has both a temporal and a spatial dimension. The life of an individual can be conceptualized as a continuous path through time-space. On the time dimension the biography of an individual can be apprehended as consisting of personal daily, weekly, paths etc. (Hägerstrand 1970, 1973, Pred 1981d), while a project consists of "entire series of tasks necessary to complete any intentioninspired or goal-oriented behavior" (Pred 1984a: 281, Hägerstrand 1973, 1982). Path and project thus refer to the material continuity of human existence. These concepts can be employed to depict the routines and practices of the spatio-temporal constitution of (1) the everyday life of individuals and (2) the sphere 
of institutions and organizations where individual paths become tied to institutional projects, e.g. regions. It is human action through which the last mentioned quite literally take place.

The most important contribution of timegeography to geographical thought is presumably the methodological one: that it calls for an analysis of the production and reproduction of the routinized practices of everyday life, it requires that the role of time and space should be reflected in day-to-day life, and more generally in the dialectic between individuals and the structures of society. Paths and projects describe the objective framework of one's everyday routines. One problem is of course, how to subsume the subjective dimension of day-to-day life into a framework, i.e. how to reach the lived experience of individuals (cf. Mărtensson 1979). The day-to-day life of a human being always consists of the experiences which he or she has lived through. One implication of this statement is that the humanistic interpretation of space does not necessarily conceive of place as an inert, experienced scene, inasmuch as for individuals a place is the only dynamic sphere in which to enact one's life, to reproduce it and to create one's place in day-to-day practices. If the concept of place is reduced in an impersonal manner to merely the routines of everyday life or to "meanings" in the sense in which some humanistic geographers have apprehended it, i.e. the "ordered world", it becomes unmistakably static. Humanistic geographers often use the word "meaning", but as Parkes and Thrift (1980: 23) remark, it is not always clear what exactly it is that is supposed to have "meaning".

Identifying a place as a historically contingent process poses a question of what is the role of personal meanings and experiences in everyday life, but at least equally important are such questions as where these meanings emerge from and what the mechanisms are that produce and reproduce "meanings" and frameworks for apprehending them. These problems undoubtedly turn the perspective to the other side of man's existence: the human being as a social actor in society.

The arguments for the separation of region from place arise from the fact that individuals are not alone in the world. Thus to understand a place as primarily an individual category and phenomenon does not detract from the very fact that single persons, individuals, are part and parcel of larger social webs, i.e. groups, communities, classes and organizations, which in the last resort come into being through practices and interests which disclose the positions of individuals in the division of labour in society. Consequently, although place is comprehended here as fundamentally an individual category, it does not contradict the institutionally mediated structures of signification, domination and legitimation, since in the reproduction of social life these structures are reconstituted precisely through the agency of individual practices.

Place is structured on the basis of everyday practices, but this does not imply any restriction to the immediate environments of individuals, even though it is naturally the everyday environment that becomes familiar in the practices of day-to-day living. In everyday life different regions and localities may transform themselves to constitute a part of one's place. Consequently the distinction between region and place is not based on the scale or areal extent of these spatial units, but instead on their relationship to one's daily life. As Tuan (1975: 159, 1976: 269, cf. Buttimer 1976: 284) proposes, a nation-state can also be a place, or a centre of meaning, for its inhabitants, and it can be much more significant than the regions lying between one's everyday environment and the nation-state. Regions like these are far too big to be experienced directly, and their "territorial symbolism", i.e. the institutional practices reproducing the existence of the material continuity of the region and its role in social consciousness, will also be weaker than that of a nation-state. As a matter of fact place and region usually coincide in the case of a nation-state, which is the most powerfully symbolized regional level and whose non-local rationality very effectively penetrates the local lifeworlds of individuals by means of various institutional practices. The aims of social reproduction, and thus socialization, for instance, in the case of the educational system and the most significant mediators of national identity (e.g. language) are usually most effectively employed at this level. The nature of territorial symbols is by no means the only and most significant distinction between nation-states and the regions of "medium-size". Much more notable is the fact that nation-state apparatus normally possesses a much deeper and more obligatory power 
relationship over its inhabitants than the institutions of subregions: "the state is a supreme coercive authority" (Gore 1984: 237). In the extreme case the representatives of the political-bureaucratic elites of a state are justified in demanding that the inhabitants should lay down their lives in specific situations if necessary.

This deeply individual and human role of place also differentiates it from the concept of locale, discussed especially by Giddens. Giddens' (1981: 131) statement concerning the similarity of his conceptualization of locale to the concept of place favoured by Tuan (1978) is presumably based on Tuan's definition of the relationship between space and place, that "place is structured space" and "Place is any locality that has significance for a person or a group of persons". Nevertheless, despite the definitions above, it seems that the concept of place employed by Tuan and other humanistically oriented geographers is more explicitly based on the experienced and personal dimensions of place, or on place as a "centre of meaning", than the concept of locale coined by Giddens, the latter being more explicitly connected with the social practices of society. If a locale is essentially a setting for interaction, a place is essentially a product of experience, both being continually changing. Settings of interaction in Giddens' way of thinking are not solely given physical environments or "backdrops" for interaction. Locales are actively organised by participants in the production and reproduction of that interaction (Giddens 1981: 161). Giddens nevertheless does not put explicit stress on human experience as regards the constitution of locales as humanistic geographers do with places. This arises from his position concerning the domain of the theory of structuration (Giddens 1984: 2): "the basic domain of study of the social sciences, according to the theory of structuration, is neither the experience of the individual actor, nor the existence of any form of societal totality, but social practices ordered across space and time". In a sense a locale is an "objectified" place. Compared with the concept of locale coined by Giddens, Pred's (1984a) theory rests on the concept of place and region as constantly becoming, and dynamic products of human action (village, metropolis, agricultural area, urban industrial complex), as concrete and objective spatial units with a continuity.
In other words, place is what takes place in a time-space specific context: "place is not only what is fleetingly observed on the landscape, a locale, or setting for activity and social interaction. It also is what takes place ceaselessly, what contributes to history in a specific context through the creation and utilization of a physical setting" (Pred 1984a: 279). Inasmuch as his framework also 'objectifies' regions and places, Pred does not explicitly consider the role of human experience in the constitution of one's everyday life or places and regions.

As regards the conceptualizations of humanistic geographers, it is an arduous task to distinguish even conceptually the experience of single individuals and that mediated by and represented in different institutional practices of society from the perspective of social theory. Tuan (1977) e.g. does not make any profound distinction between an armchair and a nation-state as a place, for instance. Consequently the mechanisms that mediate the idea of solidarity as regards the non-local, larger territorial units often remain obscure in a humanistic position. This appears to result in part from the very fact that humanistic geographers in general do not usually elaborate the nature of communities, and finally the role of nation-state, in the constitution of a 'sense of place' or feeling of belonging to larger territorial units. Pred (1983: 50) is doubtless right when he states that the impression is all too often conveyed that a sense of place is the product of an autonomous mind freely interpreting the world of experience, memories, meanings and attachments flowing from independent actions inspired by independent intentions. These premises are of course insufficient from a social science perspective, but they obviously hit the target much better as far as the real, experienced everyday life of individuals is concerned.

\section{Region and place in the present study}

The concept of region - like place - is understood here as an abstraction to be realized in the relation between individual action and social structure through the structuration process of the society. Instead of the mancentred category of place, a region is interpreted as a category with an explicit collective dimension which represents institutional practices and the history of the region, not the 
history of an individual as a place does (cf. the discussion of Habermas, 1979, about individual and collective identity). A region is mediated in our everyday life in the form of various symbols, which are the same for all individuals in the one region, though the meanings associated with them will always be construed personally on the basis of the individual's life situation and biography. In a sense, regions as symbolic structures transcend everyday local, face-to-face social interaction, and the symbol systems of regions are ultimately based upon non-local control and transactions (cf. Pred 1985b: 340). Hence though the regions of a society obtain their ultimate personal meanings in the practices of everyday life, these meanings cannot be totally reduced to experiences that constitute everyday life, since a region bears with it institutionally mediated practices and relations, the most significant being the history of the region as a part of the spatial structure of the society in question.

In general, regions can have different meanings for individuals living in different societies. Similarly their role as a part of the spatial structure of the society can vary. The existence of these meanings can be fully comprehended only by analysing the process which has created the region concerned as a part of the social and spatial division of labour in society. As products of history and social action, the regions are not outcomes of autonomous forces and do not come from nothingness. Rather, they imply both historicity and control (cf. Berger \& Luckmann 1976: 72). The functional differentation of society which manifests itself in the form of the spatial division of labour and reflects the consequences of economic, political and administrative practices, etc., also manifests itself in the differentation of the structures of society (e.g. social status, power). Pred (1981b) emphasizes that the institutional projects that are incorporated in personal paths each day, represent power and authority in institutions. The institutions themselves do not necessarily possess power, but are usually a material (or intellectual) expression and medium of practice specific power relations (cf. Gore 1984: 240). As far as the emergence of regions and regional consciousness is discussed, interesting fields of action for power relations include the varying roles and interests of opinion leaders and persons, groups, classes and organizations which wield power and which are continually involved more or less consciously in reproducing the structures of signification and legitimation regarding the nature of the regional community on different scales (region $\rightarrow$ nation-state) and in mediating and maintaining the notions which define the nature of regions. As a consequense of the division of labour, some people and groups (elites) specialize in the active production and reproduction of regional consciousness, ultimately by maintaining the established, institutionally mediated structures of signification. The purposes of these groups and individuals can vary from purely cultural interests to economic and political ones. In this respect social consciousness and thus also regional consciousness is a sphere in which the power relations in society reflect different interests and ideologies. Inasmuch as this is a question of the field of communication, the groups which dominate communication obviously also dominate the reproduction of consciousness and ideas concerning the nature of the sociospatial reality. In practice even conflicting interests usually coincide when it comes to specific regional interests arising from the cultural, economic, political, etc. conditions of the region in question. Moreover, people in certain fields, to use the expression coined by Bourdieu (1977, 1985a, 1985b), have common fundamental interests in modern societies, due to the continually deepening functional differentation in society which makes more and more anonymous people more and more dependent on each other (6).

All in all, the distinction between region and place appears to be a profitable one when contemplating the relationship between individuals and the institutional sphere which mediates the actions of individuals and the logic of society from the perspective of spatial structure. Hence it is the place where an individual reproduces his material and intellectual existence. This is structured through participation in social actions and in interaction with other people and institutions, and through the meanings given to these. One's place ceases to exist when one dies. The region, on the other hand, is an institutional sphere of longue durée representing one specific dimension of the spatial structure of the society. Although a region is a contingent historical process within the society, just as is a place for an individual, the former, because of its institutional role in the 


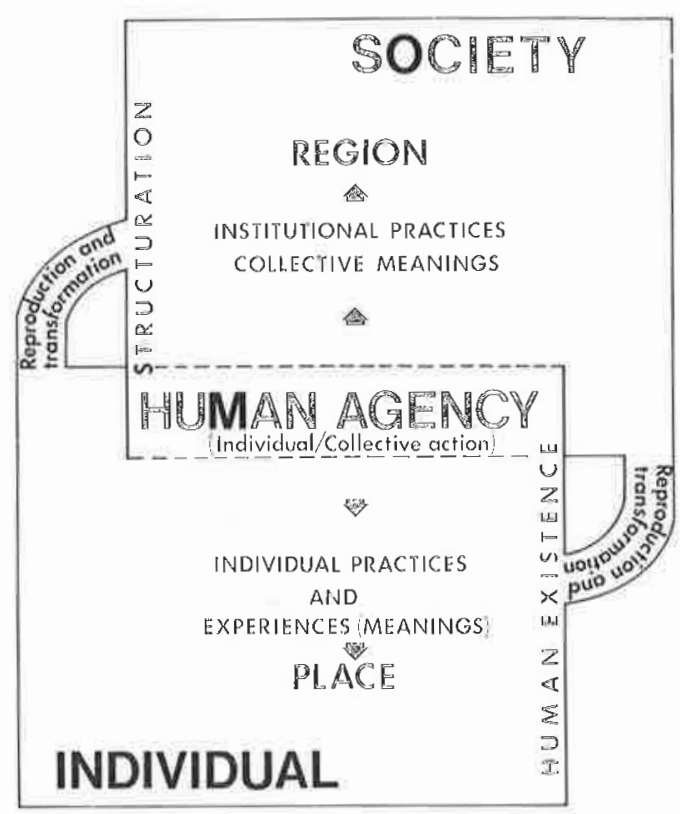

Fig. 1. The emergence of regions and places.

society, manifests itself in a more permanent structure (Fig. 1).

After these preliminary deliberations it is now time to turn the perspective to the history and logic of the study of geography and discuss the nature of region more profoundly by analysing traditional definitions of the concept.

\section{'Th he concept of region in geographicall tradition}

\section{Some definitions}

In geographical discourse a region is commonly regarded as a part of the earth's surface which possesses a quality of cohesion derived from a consistent relationship between associated features. It is this quality that distinguishes it from the concept of area which usually contains no implication of homogeneity or cohesion but is merely a geometrical portion of earth-space (see Whittlesey 1954: 22, cf. Robinson 1953, Dickinson 1964: 3). It must be emphasized, of course, that the regions are always defined by specific homo- geneity criteria, determined by each piece of research (Whittlesey 1954: 32).

At the beginning of the present century geographers in several countries began to adopt concepts of region which had been elaborated in different physical, intellectual and social environments (Landschaft in Germany, Paysage in France, natural region in England, etc., see Granö 1978, 1982). In general it is justifiable to suggest that this took place at time when geography had - as a manifestation of external goals in society - become an institutionalized academic discipline, while at the same time these new concepts were an explicit manifestation of the internal development and the emerging identity of the discipline (see Granö 1981).

In spite of the many discrete concepts of region, the view on geography as a discipline focused particularly on regions is closely connected with chorological thought or the study of areal differentation, which was an important methodological approach in the history of the science, e.g. in German and Anglo-American geographical research up to 1950 (see Hartshorne 1939, Hettner 1927). Later, especially under the guidance of North American geographical research, this was gradually replaced by the spatial approach, in which scholars took their basic methodological category from distance (and space) and hence from interaction (Harvey 1969). Notwithstanding these developments, region still preserved its position as one of the basic categories of geographical thought, now as an instrument to be applied to the classification and organization of geographical information and as a framework for regional systems. Region had already been an essential notion from the viewpoint of classifications in earlier times, however, and had been employed for organizing manifestations of the material world (natural and cultural phenomena) for practical and technical purposes (e.g. planning). The emphasis on the word "material" points to the dominating trend in geographical research, which has usually ousted the subjective element, e.g. the ideas of men about their places, regions, landscapes, etc. Even though the problem of the subjective dimension of regions has been present in discussions concerning the nature of regional geography, these ideas have been overshadowed, mostly by the positivistically oriented spatial approach (Paasi 1983). Although it can be suggested in general that 
positivistic thought began to dominate AngloAmerican geography in particular, there have been some subareas of geography whose practitioners have not inevitably been inspired by this trend (historical geography, for instance, see Guelke 1975).

The subjective dimension of regions has been a focus of discussion mainly from two perspectives. Firstly (1) one should note the holistic perspective that manifested itself in German geography during the first decades of the present century. In the spirit of the general philosophy of life (Erlebnis Philosophie), some German geographers were interested in the totalities of "Landschafts" and even in their aesthetic qualities (Schultz 1980). The concept of region was in most cases reduced to the visible landscape. This model of thought was partly transferred to North American cultural geography by C.O. Sauer (1925) and his colleagues. The portrayals of regions in traditional regional geography in different countries have at times contained elements which can be called 'humanist' or at least aesthetic. The role of the subjective dimension in regional geography has also been an object of methodological discussion in the geographical traditions of many countries (Paasi 1983: $90-144)$, but it was not until the emergence of (2) behavioural and humanistic geography that geographers were commonly interested in how average people see and interpret landscapes and regions. As geographers, they were previously usually interested simply in how to portray their objects of study more elegantly.

It was at his point that a conscious philosophical and methodological alternative to the positivistic approach arose in geographical research. These approaches have introduced new images of man into geographical thought, manifesting themselves, both in methodological discourse and in concrete studies, in a need to take into account the subjective dimension of man's behaviour and, more profoundly, man's existence. The concept of place in its modern meanings, discussed on the preceding pages, is a concrete product of the deliberations of humanistically oriented geographers. The concept of region, on the other hand, has not been put forward in recent discussions in a way that represents any methodological or philosophical progress. Behavioural and humanistic geographers have underlined the significance of analysing and understanding the subjectivity and experiences of man in relation to his environment, but they have not deliberated on the question of the essence of a region.

What, then, have geographers written about the nature of regions or their constitution at different times? It is fruitful to begin with the definitions presented by the representatives of chorological thought. Richard Hartshorne (1959: 130), for instance, writes as follows:

". . . a "region" is an area of specific location which is in some way distinctive from other areas and which extends as far as that distinction extends. The nature of the distinction is determined by the student using the term; if not explicitly stated, it must be judged from the context'".

The definition presented by Whittlesey (1954: 30) contains the same idea:

"Any segment or portion of the earth surface is a region if it is homogeneous in terms of such an areal grouping. Its homogeneity is determined by criteria formulated for the purpose of sorting from the whole range of earth phenomena the items required to express or illuminate a particular grouping, areally cohesive. So defined, region is not an object, either self-determined or nature-given. It is an intellectual concept, an entity for the purpose of thought, created by the selection of certain features that are relevant to an areal interest or problem and by the disregard of all features that are considered to be irrelevant".

The definitions presented above (1) are geography-centred and (2) begin from the concept of region itself. The latter fact contains implicitly the idea of a geographical region as a kind of entity (although not necessarily an object), which geographers have to discover or produce as a result of the research process. Hence the ultimate nature of geographical regions will be defined on the basis of research problems, whatever they may be. The region is essentially a mental category to be employed in classifying or organizing geographical data (see Hartshorne 1939, Kostbade 1968, cf. Entrikin 1981b). The most difficult problem for the conceptualizations like this is that they basically reduce the region to a static, stable entity, rather than a developing, transforming and continually reproduced expression of time-space specific relations and structures in society. Classical descriptions and interpretations of homogeneous (or uniform) regions have of course been, and still are, important and necessary for human beings and for their practical purposes. They are means of 
making the world clearer and more graphic. Methodologically, however, the problem is that definitions like those above emerge ontologically from the reality of the discipline, not from that of the society, which means that space is separated from social processes.

In this respect the concept of functional region, the evolution of which is closely connected with the development of geographical thought in the spatial tradition, is more explicitly related to the spatial structure of human practices and thus advances further from the pure abstraction of region. In practice functional regions are classifications of the facts and processes of society and hence are significant in administration and planning within the society. This being the case, geographers have established a relation with the public sphere of society as power holders and may sometimes have played a substantial role in legitimizing the formation and emergence of new regions. In other words, the results of functional classifications will have been used as technical instruments to analyse the socio-spatial processes in society. Especially for geographers who regard their subject as a spatial science, region has become important as a technical category to be employed in various classifications, i.e. in regionalization. The concept of region implicit in this starting point is ". . . a part of the earth's surface which is distinguished in some defined way from the surrounding area" (see Grigg 1968: 464, cf. Harvey 1969: 125, James 1972: 460). Consequently the concept of region which forms the basis for classification does not necessarily differ essentially from that involved in chorological thought performed by the representatives of regional geography.

An analysis of the definitions given of the geographical concept of region shows that the essence of regions is commonly discussed from the same point of view. Hence crucial problems (in connection with regional geography) have been the nature of geographical description and its constitution (from rock and soil to human ideologies) and as far as geography's basic categories are concerned, the nature of the concept of region, i.e. the logical (conceptual) meanings of a region. Discussions of the latter have usually been restricted to formal or functional regions and to their roles as means of classification. Although the relationship between geography and history has always been an interesting question in the methodology of the institutionalized discipline of geography, this fact has not manifested itself in the definitions of geographical regions. As seen above, not only methodologists but also historical geographers have laid stress on the role of the historical perspective in geography, but this state of affairs has not been reflected in the definitions of region. If one considers that a dictionary of a discipline can be analysed as an indicator of the development of the conceptual basis of the subject, Derek Gregory (1981a: 283-284) may be said to introduce into "Dictionary of Human Geography" only the traditional ideas of region, even though, as a methodologist of human and historical geography, he has been interested in regional transformation as a social process in his own work (Gregory 1978: 171, 1982c).

\section{The region as a community}

Questions concerning the nature of the relationship between regions and the communities of their inhabitants, people in their spatial setting, specific regional ways of life, etc., have for a long time been among the central problems of human geography (see Buttimer 1968, Pahl 1965, Jones 1965). During the rise of humanistically oriented geography "community', "milieu" and "region" again became important categories in geographical thought (see Entrikin 1981a). Geographers have thus not always started out from the basic geographical concepts themselves when elaborating the essence of regions. As members of concrete societies, they have at times emphasized the existence and formation of specific cultural regions which are canonized in the minds of their inhabitants and/or outsiders. In North American cultural geography, for instance, there has been a long tradition of examining vernacular regions, i.e. the products of the spatial perception of average people (see Jordan 1978, Zelinsky 1980, cf. Finch 1939, Tuan 1975). In this respect an interesting article concerning the formation of a region has recently been written by Shortridge (1984, cf. Shortridge 1985), who explores the emergence of the "Middle West" as a distinct cultural area starting from the 19th century as a consequence of social processes. According to Shortridge, the social and political rift between the East and the Central Plains 
in the 1890s was the immediate factor in establishing the 'Middle West' as a distinct cultural region. The role of this region in the collective consciousness of the nation then varied with time, until it finally came to symbolize the nation. An interesting framework for the empirical analysis of the emergence of regions has also been developed in the article by Meinig (1972) on "American Wests". Meinig's framework suggests a focus upon following regional features: population (numbers and areal distribution), circulation (traffic patterns within and between regions), political areas (basic jurisdictional territories) and culture (selected features characteristic of the local society and its imprint upon the area) (Meinig 1972: 161).

In a methodological discussion, Hart (1982: 23, see also Kostbade 1965: 364 note 3) has pointed out the changing role of regions: "You cannot understand a region until you understand how it came to be the way it is, and how it is changing. Present patterns are but a momentary reflection of continuing processes of change, and we must be sensitive to the direction and rate of change, both past and future" (cf. James 1954: 14). Inasmuch as the regions do not arise from nothingness, Hart's statement also implicitly contains the role of man and social institutions as forces influencing the emergence of regions. Another implication is the relationship between a region and its inhabitants, although Hart does not discuss this any more profoundly.

The definitions do not inevitably conceive of a region as a community of inhabitants, although this idea is at times subsumed in discussions concerning the nature of regional consciousness in particular, in speculations on the personality of regions (e.g. Gilbert 1960 ), and in discussions about regions as organisms. As is well known from the history of the discipline, the holistic ideas connected with the nature of regions as organisms culminated in the mystical thoughts presented in German geography in the 1920-30s. Such ideas as ". . . community and region are but aspects of the same organism" (Stevens 1939) appear to be motivated by premises other than scientific ones (see Hartshorne's, 1939, critical review). But even today organism analogies have not entirely disappeared from science or social practice in general. Gore (1984: 230), for example, argues that new territorial strategies of regional planning at various scales (the district, the region, the nation) approach these territorial units as if they were organisms.

The psychological relationship between a region and its inhabitants has also been noted in methodological discussions. Whittlesey (1954: 53), for instance, writes as follows: "A region clearly aware of itself is likely to appear to its inhabitants and to outsiders to have an independent existence. This psychology is an element of the regional complex". The relationship between individuals (and groups) and their region has been a matter of relevance in the tradition of regional geography in many countries. Especially at earlier times it was usual for geographers, when defining the nature of their discipline or its subareas, to point to the unity of the people and their regions, common sets of values or even mentalities of individuals in the spirit of collective psychology (see examples in the review of the concept of social geography by Buttimer, 1968). The employment of the concepts character or mentality, which are typically concepts of individual psychology, can easily lead to unreflected stereotypical thinking, allowing regional stereotypes to guide our thinking. When pondering over the differences in behaviour, reactions, etc. between people living in different regions, it seems to be more justified to talk about of cultural features, which have an explicit collective dimension, than to discuss collectives by means of concepts which apply to individuals (see Paasi $1984 c)$.

In geographical speculations concerning the nature of regional consciousness one can quite often observe at least some implicit ideas to be similar to those postulated by idealistic philosopher Royce at the beginning of this century. The starting point of Royce's provincialism was the concept of province, which is, according to him, "any part of a national domain, which is geographically and socially, sufficiently unified to have a true consciousness of its own unity, to feel a pride in its own ideals and customs, and to possess a sense of its distinction from other parts of the country" (cit. Entrikin 1981a: 218). Entrikin's (1981a) article on Royce's provincialism includes attractive proposals for a conceptual analysis of the problem of the regional community. Royce's idealism and holism, which took the form of an abstract idea of group consciousness or 'spirit' at different regional levels, contains much that is reminiscent of notions 
put forward by geographers in their deliberations on regional consciousness. If the relationship between a region and its inhabitants is taken ahistorically and as given, speculations on the existence of different "regional spirits" are, Entrikin (1981a: 223) states, unacceptable to most contemporary geog. raphers, especially those interested in the constitution of the socio-spatial relations and consciousness that mediate in the relationship between individuals and society. Consequently it is essential to discuss and analyse the nature of loyalties more profoundly with respect to different regional levels ("communities') starting from one's place and going up to regions and finally the nation-state, since it is an undeniable fact that these communities vary in nature at different levels of spatial structure and in their relationship to the dayto-day life of individuals. It goes without saying that the mechanisms that socialize inhabitants as citizens also vary greatly at these levels.

The personification of a region expressed in the quotations above may sound mystical, but it does serve to direct the discussion to a fundamental question concerning the region as a human spatial unit: does there really exist a feeling of 'togetherness' among the inhabitants of a region, and if so, how has it built up during history, or is this a question of a written identity replesented in the institutional sphere (e.g. the mass media) as an expression of social control and thus power. What are the forces and institutions that cause perhaps hundreds of thousands or millions of people who have nothing to do with each other to feel that they form a "community"? The personification of regions is a notorious problem in the language used in international politics and within nationstates (see Fromkin 1981: 37). The problem can expressed in general terms as follows: who are the real subjects in international (or interregional) intercourse, territories or elites in a society as representatives of institutional power? Problems like these also contain an ethical dimension concerning the work of geographers.

The idea of the existence of abstract (reference) communities implies in social practice the question of territoriality. At higher group levels, the role of social and cultural perspective has been emphasized in the constitution of "symbolic regions" that everyone has in his or her mind (Paasi 1984a). The socialization process inevitably communicates to in. dividuals the idea of "our region", since, as Soja (1971) remarks, nearly all the characteristics which distinguish man from other animals (culture, the degree of dependence of symbolic learning, knowledge of history and tradition, language etc.) are attuned to the maintenance of integrated groups. Thus it is misleading and even dangerous in the case of nation-states (and their power-relations), for instance, to discuss territoriality purely in terms of biological analogies (cf. Gottman 1973, 1982, Knight 1982).

Problems like those elaborated above direct us to ask such questions as what is the nature of "regional consciousness" in relation to consciousness in general, how does it emerge, how does it manifest itself in social practice, what are its practical consequences, how can it be developed and manipulated etc. Regional consciousness has been largely overlooked in the geographical literature, although, as will be seen on the following pages, geographers have at times subsumed it within their deliberations.

On the basis of the above discussions concerning the nature of a geographical region, the following chapters will analyse the essence of regions as results of a process whereby the interaction between the structures of society and actors create regions as a consequence of intentional actions. The aim is to conceptualize the process which pro duces and reproduces regions and regional consciousness as special reflections of social space.

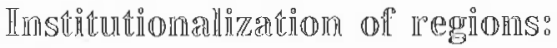

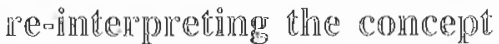

\section{T'he regior as at thuman and social category}

When the role of regions - as well as places - is discussed and analysed by taking them as human and social categories, the definitions presented above appear to be onesided al though they doubtless illustrate some parts of the spatial structuring of human reality. Ontologically it seems, however, that to start from the discipline of geography itself when defining the concepts it employs is liable to 
become a conceptual prison which prohibits one from delving any more deeply into the structures of human and social praxis. The definitions discussed above in general lack any perspective that could promote an understanding of the essence and emergence of regions as parts of society.

Because human beings live in some specific society and the regions are always located accordingly, the development of society is the logical point of departure when discussing the nature of regions as human and social phenomena. Space and its symbolic and ideological dimensions, as well as its material basis (e.g. nature, economic development), are essentially social categories, and thus essentially reflect the development of the society (cf. Soja 1985a, 1985b, Urry 1981, 1985, Williams and Smith 1982). As Soja (1980: 210) notes, although space itself may be primordially given, its organization, use and meanings are products of social translation, transformation and experience. In the present study the concept of space serves to help us to understand how individual and social practices are structured and conceptualized in the course of the development of a society. The point of departure is to discard the distinction between space and society, a dichotomy that is most clearly expressed in deliberations concerning the nature of geographical space, promulgated particularly by the representatives of the spatial tradition. Such deliberations are quided by the purely philosophical and geometrical concepts of space developed in (classical) physics (see e.g. Harvey 1969). Following the 'reborn' Harvey (1973: 13), it is reasonable to point out that "The problem of the proper conceptualization of space is resolved through human practice with respect to it. In other words, there are no philosophical answers to philosophical questions that arise over the nature of space - the answers lie in human practice" and further, with regard to the constitution of social life, "To be alive is to participate in the social production of space, to shape and be shaped by constantly evolving spatiality which constitutes social action and relationship" (Soja 1985b: 90).

The definitions put forward on the preceding pages naturally depict some features of the regions of a society but they do not necessarily reach the process during which the regions have emerged to constitute a part of the dynamic spatial structure of that soci- ety. Moreover, they do not give any instructions for tracing how the ideas connected with the regions have come into being in the course of the history of the society, how the functional roles of the regions have emerged, how the meanings associated with the regions in social consciousness have taken shape, etc. Gregory (1978: 121) cites the expression "fetishism of area", by which he refers to the view of a geographical region as a special entity which can interact as such with other regions as if the regions were a world apart from society. It is abundantly clear that when the regions are viewed as human and social categories, the fetishism of regions must be abandoned. The regions have to be conceptualized and analysed empirically as a part of the historical development of the society (see also the criticism of Urry 1981, 1985: 28).

On the following pages the region is understood not as a pure concept which can be totally reduced to the ideas of individuals whether scientists or not - neither is it understood as a purely technical category which can be applied only to the classification of physical and cultural phenomena so as to create logical order on the terrestrial surface of the earth. Rather a region is comprehended as one expression of time-space specific relations and structures of society, being formed through the development of the society, the latter with its structures also being a part of the global organization of sociospatial reality. When speaking about the regions of some specific society at some moment of time, the existence of a region always represents some specific cultural and historical phase in the development of the society and consequently can be conceived of solely in this context, through its history (cf. Lee 1985). Furthermore, traditional philosophical and methodological questions regarding the ontological nature of regions, their objectivity or subjectivity, the nature of their boundaries, etc., can get no answer from purely logical (conceptual) sources, but instead these problems have to be placed in the specific historical situation of the society. In this way questions concerning the essence of regions become questions of their origin, emergence and disappearance (transformation). Hence regions can come and go along with the development of society according to a relatively independent logic, which is based on the traditions and history of the region and 
Fig. 2. The interacting stages of the institutionalization of regions.

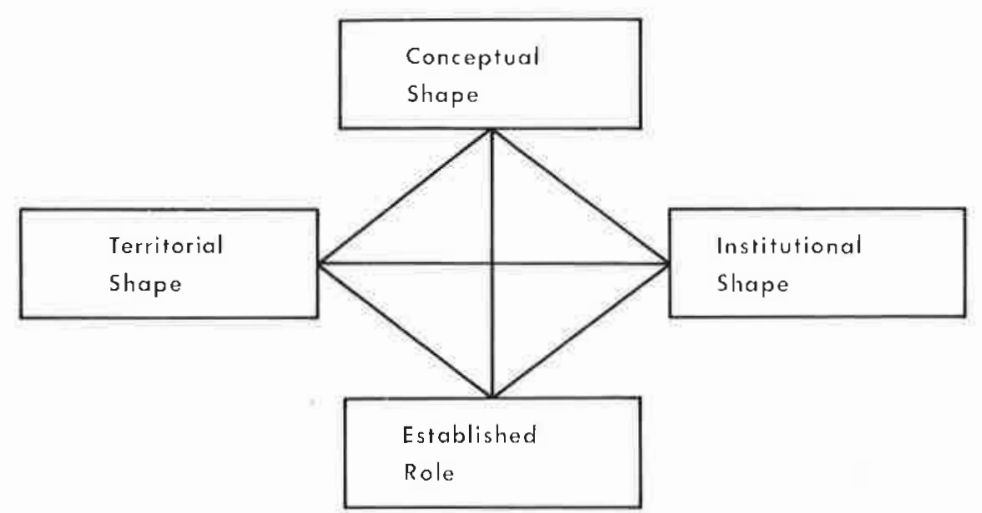

on its role as a manifestation of the division of labour in society. The institutional sphere in which the regions are represented continues its existence because one's role in its reproduction can always be (and is) replaced by someone else. Places, as defined above, always follow us. When we die, we carry our places with us.

\section{Institutionalization of regions}

It is presumably not very sensible to try to state exhaustively in a sentence or two what a region really is. Instead, in order to understand the emergence and development of a region, it is reasonable to divide the concept logically into stages, which express different aspects of the historical formation of concrete regions in a society. It is practicable to distinguish four stages in the process of institutionalization of a region: 1) assumption of territorial shape, 2) development of conceptual (symbolic) shape, 3) development of institutions, and 4) establishment as part of the regional system and regional consciousness of the society concerned (see Fig. 2). Inasmuch as the division put forward above is a theoretical one, it does not work similarly with all regions, and in practice the stages do not always follow each other as they are presented here. They may be entirely or partly simultaneous, or they may be ordered in different ways. Instead of the traditional definitions, regions are conceived in present framework as special products of the development of society: regions emerge and disappear and the regional divisions of a society undergo gradual transformation as spatial manifestations of social processes.

The institutionalization of a region is a socio-spatial process during which some territorial unit emerges as a part of the spatial structure of a society and becomes established and clearly identified in different spheres of social action and social consciousness. Conversely, as regards the individual actors and groups in a society, the emergence of a region can be looked on as a consequence of the goals established and the decisions reached by local or non-local power-holding individuals and/or coalitions of individuals operating in the context of the ongoing structuration process (cf. Pred 1983: 53). In the course of the institutionalization process a region will be continually reproduced in individual and institutional practices. The institutions of a society (economic, political, legal, educational, cultural, etc.) will eventually be the most important factors as regards the reproduction of the region and regional consciousness.

The areal extent of the idea of region set out here is not confined to any specific regional level. Hence a region can just as well be a part of a city, a municipality or a county, as a province or nation state. The socio-spatial extents of regions naturally affect the nature of their institutionalization process. The lower the "presence availability" (the role of faceto-face interaction between the inhabitants), the more complicated are the time-space specific individual and institutional practices that produce the territorial unit as a manifestation of socio-spatial processes, which in turn reflect the history and traditions of the society concerned, and since local control diminishes 
as a region becomes larger, the more complicated also are the power relations structured into the process. Inasmuch as 'social' and 'spatial' manifest themselves as an interwoven process in a society, the institutionalization of some specific region is always connected with the socio-spatial structure as a whole. As a fundamental basis for the emergence of regions, it is also important to note the variable, time-space specific, role of physical conditions, which Thrift (1983: 39) groups under the general heading of "topography" (geology, hydrology, climatic conditions, etc.), and the spatial organization of production and the division of labour. The roles of these factors and their interrelations vary markedly depending on the size of the territorial unit concerned.

\section{Structures of expectations}

Before considering the stages in detail, it is essential to broaden out the conceptual basis of the present study. As far as the relationship between a region and its inhabitants (and also outsiders) is concerned, the concept of structures of expectations appears to be significant for comprehending the emergence of a region and its regional identity. The concept has been employed in linguistic and cultural research to depict the ways in which people organize their knowledge of the world and use it to generate interpretations and relationships with regard to new information, events and experiences (Ross 1975, cit. Tannen 1979: 138-139). These structures are based on one's experiences of the world in a given culture (or combination of cultures). The discourses of human geographers and other social scientists employ several expressions to represent the same idea, the best-known among which are "structure of feeling", coined by Raymond Williams (1961), and "habitus", employed by Pierre Bourdieu (1977, 1985a). According to Williams (1961: 48-71), structure of feeling is a particular sense of life, a distinct sense of a particular, native style, or "a particular community experience hardly needing expression". Structure of feeling appears to be explicitly connected with specific social groups and timespace specific situations. Williams strongly emphasizes generations, for instance, as groups which are distinct from each other as regards their structure of feeling (7). "Habitus" is produced by the structures constitutive of a particular type of environment (Bourdieu 1977: 72). It is a product of history which produces individual and collective practices and, therefore history, accordingly with the schemes engendered by history. Also, "the habitus is the universalizing mediation which cause an agent's practices, without either explicit reason or signifying intent, to be none the less 'sensible' and 'reasonable'" (Bourdieu 1977: 79).

Both structure of feeling and habitus appear to be explicitly bounded by a specific "way of life" with its general modes of thought. The concept of structures of expectations is employed in the present study as a scheme that is more explicitly bounded by a specific region, being relatively permanent (traditionbounded) and mostly represented in the form of time-space specific, region-bounded, institutionally embedded schemes of perception, conception and action. In this respect they can be regarded as specific vehicles of social (and spatial), classification. Thus they are not inevitably bounded distinctively by generations, for instance. Cultural research employs the concept of structures of expectations when concentrating on the sphere of culture, but here it will be employed in a wider sense to refer to both the physical and the cultural character of a region. These structures can comprise real, imagined or even mythical features of a region, including ideas of the mystical character or mentality of its inhabitants, for instance. Citing freely from Edmund Leach (1970), regional myths can be "true like god for those who believe in him but a fairytale for those who do not" (8).

The basis for structures of expectations lies in the process of socialization during which concepts of the world are adopted. Giddens (1979) places emphasis on the fact that socialization occurs through participation in institutional practices and persists through adulthood. The most significant context for the socialization of a child is his or her family, while in Western cultures the formal education system and the mass media are also crucial (see Jahoda 1978, Bourdieu \& Passeron 1977). Institutions capable of constituting socio-spatial (territorial) demarcations are of particular importance as far as the production and maintenance of structures of expectations is concerned. 
Structures of expectations constitute a crucial concept for the present study for several reasons. Firstly, they facilitate an understanding of the special character of regions compared with places, since in the case of regions we can speak of a collective spatial role which is expressed in structures of expectations. This role is based on knowledge or beliefs concerning the historical and cultural features of a given region, which are gradually reproduced in society, not necessarily by the institutions of the region itself, but also by external, non-locally controlled institutions (e.g. the education system). Hence the collective, institutionally mediated roles expressed in the structures of expectations are essential as for the transformation of regions into places, centres of feeling of belonging to time-space specific, more or less abstract reference groups or communities. One of the most important collective qualities of structures of expectations is without doubt language, which constitutes the basis for communication, since language is the medium through which speakers and hearers realize certain fundamental demarcations (Habermas 1979: 66). Pred (1984a, cf. Thrift 1983) lays stress on the importance of language as follows: It is "fundamental to the bringing off of path-project intersections because it provides a foundation for describing, grouping and differentiating things, events, and experiences and because it can be equated with intention-affecting ideology and the sustenance of social domination", and also, as regards places, "the limits of a population's language mean the limits of their place... at the same time that the limits of their place mean the limits of their language ..." (Pred 1984a: 285). Everyday life is action with "others" with and by means of a shared language (Berger \& Luckmann 1976: 51). This is especially significant for the identity of ethnic minorities (see Liebkind 1984). In everyday discourse language is a significant apparatus for social classification between different groups and classes in local "language markets", while in terms of the collective role expressed in the structures of expectations, language turns out to be of importance for socio-spatial classification, especially in the case of "their" regions. Dialects, for instance, are popularly thought of as collective, region-bounded features, as if they transcended the effects of social differenta- tion in society. Dialects have for a long time been an essential part of the structures of expectations in different parts of Finland, for example (9). In one's day-to-day life it is obvious that the conflict between my collective spatial role ("us") and "theirs" turns up most clearly when changing the region where "I" live, in a "crisis" of everyday order (cf. Bourdieu 1977: 170). In one's region, the existence of this collective role is taken-forgranted in the jungle of everyday practices and routines, because there are inevitably not any regionally based challenges for the everyday order of things. In one's "own" region special features of a collective spatial role are actually manifested in institutional practices.

Secondly, as regards the reproduction of the idea of a particular region, structures of expectations form an essential part of the structures of legitimation. As Berger and Luckmann (1976: 111) suggest, legitimation has both a cognitive and a normative element: "Legitimation not only tells the individual why he should perform one action and not another; it also tells him why things are what they are. In other' words, 'knowledge' precedes 'values' in the legitimation of institutions". In the reproduction of the idea of a region the most significant tools will presumably be symbolic processes, expressing and portraying realities other than those of day-to-day local experience. Structures of expectations are essential for establishing the past (and also the future) as a common frame of reference for the inhabitants of a region. Consequently the third substantial meaning of the concept is that it provides a conceptual basis for the historical analysis of the formation of the images of a region. Behavioural geographers have been studying the images of regions for a long time, but have very seldom made any attempt to analyse the formation and content of images as a part of the emergence of a region and the development of the institutions and society concerned.

In the case of both nation-states and subregions it is sometimes an arduous task to trace how and when structures of expectations have come into being. But as far as the constitution and reproduction of social and regional consciousness is concerned, they obviously can take shape only after there are institutions capable of reproducing and maintaining them. Once a communication field with a distinct regional function, maintained by the 
practices of cultural, economic or political, institutions etc., has taken shape, the structures of expectations can remain unchanged as matters of custom even though the role of the regions in the spatial structure may change greatly in the course of social and economic development.

Cultural research has taken up the question of the disappearance of local and regional features and the factors engendering such a trend. In his geographical work, Relph (1976: 90) mentions some forces which tend to homogenize space and value systems and speaks about placelessness, a tendency through which places can lose their authenticity and identity, a "point where they not only look alike but feel alike and offer the same bland possibilities for experience"'. Factors which homogenize our local space are not usually immediately in front of our faces, "within sight or reach, but in distant seats of power" (Pred 1983: 63). Relph mentions mass communication, mass culture, big business, centralized government and the effects of the economic system as factors that produce placelessness. Pred (1983: 62-63) notes that views which maintain that the above-mentioned factors and other isolated features which are supposedly at the foundation of the weak sense of place lack coherence: "Proponents of these factors ignore the fact that sense of place is always a part of an individual's ongoing development of consciousness and ideology, a development that is one with everyday participation in time-space specific institutional practices, with socialization and reproduction and transformation of social and economic structures, with the becoming of sensed place", and further, "insofar as individuals actually possess a sense of place that is lacking in depth, it is in very large measure a result of their concrete participation in the reproduction and modification of local and macro-level social and economic structures, of the sweeping up of their own external-internal and life path-daily path dialectics in the unbroken time-space flow of the structuration process". That is to say, it is the everyday life of individuals through which the deepening functional division and specialization of labour occurs, overridden by the dominant ideology's concern for efficiency and productivity (Pred 1983: 63). As for the economic character of regions, changes in the nature of the organization of economic activities (internationaliza- tion, increasing spatial indifference, etc.), which also manifest themselves in the spatial and social division of labour, mean that it is increasingly the case that on various criteria it is now more and more difficult to identify distinctive regional entities (Urry 1983: 124). The spatial division of labour causes people to move to new environments, a global mass culture comes into our living rooms, our material and intellectual culture is becoming more and more homogeneous, and at the same time people are becoming more specialized in their work, which reduces the cultural homogeneousness of the individual regions.

It has to be recognized that structures of expectations regarding regions do not inevitably lose their role even though single local sites may lose something of their personality. As institutionally mediated structures, the essential features of a "regional identity" can be reproduced even though the "real" basis for the structures may gradually disappear. As stressed above, structures of expectations typically manifest themselves as collective portrayals resulting from institutional practices, not those of one's everyday experiences. Moreover, structures of expectations usually contain elements that represent the real or mythical history of the region concerned, and history, of course, does not disappear.

Starting out from these basic ideas and concepts, it is now possible to enter into a more profound discussion of the stages in the institutionalization of regions presented above.

\section{Assumption of territorial awarenes and shape}

The first stage in the process of institutionalization refers to the development of the social practices through which the region achieves its boundaries and will become identified as a distinct unit in the spatial structure of the society. The existence of boundaries of some kind (not necessarily physical) as a basis for social classification is the fundamental requirement for the emergence of a regional consciousness among inhabitants. This is the foundation upon which the conceptual shapes (symbolic orders with their manifestations) and institutions that com- 
mence the process of maintaining and repro. ducing the existence of the region will be constituted. The emergence of territorial shape is a process in which the power relations in society, manifesting themselves in political, administrative/bureaucratic, eco nomic and symbolic institutions, for instance, play a crucial role. As is well known, the term 'territory' carries connotations of geographical space and power (see Gore 1984:238, Sack 1983: 55). The boundaries may change in time, however, and thus the current territorial shape of a region does not necessarily disclose very much about the history of its formation (see e.g. Meinig 1972, Shortridge 1984), since many changes may have occured in its boundaries before it achieved this shape. It is important to be aware of the history of such boundary changes, as the structures of expectations of a region can sometimes comprise elements which appeal not to belong to that region today but which may have previously been part and parcel of it. The shape of a region can be fixed (e.g. administrative regions) or vague, so that the idea of a region, e.g. various elements in its stuctures of expectations (nature, culture, landscapes, stereotypes of the inhabitants, etc.) can predominate over its limits and explicit boundaries.

It is obvious that every country possesses regions that are typically vague "ideas" with more or less canonized structures of expectations reflecting the history of the area, for example. Regions that are "ideas" rather than fixed administrative entities are not usually promulgated by any central authority, but have emerged with time through interplay between the inhabitants and the institutions of society (cf. the observations of Tuan, 1977: 99, regarding the regional labels of the United States). Pairs such as Southern/Northern, Eastern/Western connected with the word Finland, for instance, do not point to any distinctly delimited regions of the councry, but they do bear specific structures of expecta tions, which vary depending on the context in which they are used. The former dichotomy is usually associated with regional policy, typically in the spirit of myth that these areas (which nevertheless have no clear boundaries) are exploiting each other, while the latter commonly refers in Finnish regional consciousness to cultural differences between the areas, which partly have a real historical basis.

\section{Development of conceptual (symbolic) shape}

During the formation of the conceptual shape of a legion certain structures of territorial symbols will become established. One item of special importance is the name of the region, which connects its image with the regional consciousness of the inhabitants and outsiders. This stage is more explicitly associated with the consciousness of the inhabitants than the first one, as the emergence of the symbolic significance of regions, i.e. the formation and reproduction of structures of expectations, depends crucially on the communication-based relationship between institutional and individual practices. The development of the sphere of social institutions and organizations in particular is of crucial significance for the establishment of the content of regional consciousness. This sphere carries with it the history and traditions of the society and reproduces social consciousness and, as a part of this, a regional consciousness. The formation of the conceptual and symbolic shape of a region canonizes an apparatus for distinguishing the region fiom all others, and constitutes the frame of reference in which the structures of expectations are grounded and by means of which they are reproduced. Symbols always symbolize something. As Martin (1981: 37) states, "one major function of symbol systems in all societies and groups is to legitimate, neinforce and celebrate the status quo - both the existence of the social per se and the particular disposition of roles, values, identifies, privileges and so on in that place and tinc". In a territorial context symbols are means of setting limits between time-space specific social realities. With regard to regions, territorial symbols are usually more or less absiact expressions of group solidarity embodying the actions of political, economic and cultural institutions etc., in the continuing reproduction and legitimation of the system of practices and institutions that characterize the region concerned. Symbol systems of regionally demarcated social lealities car be based on local or non-local control, which expresses the organization of power relations and ideologies in institutional practices (cr. Pred 1985b).

The increasing number and use of territorial symbols, and especially the emergence of a name for the region, is significant as regards the role of the time dimension. Historiographi- 
cally, it appears to be fairly customary to create a continuity for the existence of regions within history, e.g. by using the institutionalized name of a region when depicting periods during which the name was not de facto generally employed or was perhaps entirely obscure to the inhabitants or even within the institutional practices of society. This proves to be a significant device for creating a timespace specific past which does not diverge historically or symbolically from the regions or nation-states of the present. A special problem of historical continuity, that one concerning the relationship between a "beginning" and an established state of affairs for continual transformation and social reproduction, is often present in the historiography of nation-states and sub-regions. This arises from the fact that the established regional unit concerned is preferably realized and apprehended as a continual subject, not just an $o b$ ject of the actions of "others". As a fitting illustration of these problems at the level of nation-states, Smart (1983: 81), for instance, writes as follows: "Since the French Revolution, nationalism has helped to promote the writing of history as each national group tries to create, so to speak its own past. It is now common to think of history in national terms we can talk of Italian history, American, Canadian, French, Indian, Cambodian, and so on using modern political groupings in order to define the past. There was no consciousness as such of being Italian three hundred years ago: there were different regions of the peninsula under different rules. The German statesman Bismarck was not altogether wrong in referring to Italy as merely a geographical expression. But Italy emerged as a selfconscious nation and it is from this standpoint that we look backwards to the 'Italian' past. Anyway, there is a strong trend in modern times to see history as a grouping of national histories, each of which illuminates the nature of the nation in question. In brief, the story of Italy or of the United States becomes a means of creating a consciousness of being Italian or being American".

\section{Development of the sphere of institutions}

\section{Production and consumption of space}

The second and third stages in the present framework are in reality simultaneous aspects of the same process, as the emergence of institutions is naturally linked with the increasing employment of the name and other territorial symbols and signs of the region. The expansion of the number of institutions beginning to maintain the image of the region and the criteria for the identity among the inhabitants is hence of crucial importance for the reproduction of regional consciousness. The development of institutions refers here not only to formal establishment (e.g. mass media, education) but also to local or non-local practices in the spheres of politics, economics, legislation, administration, etc., as a consequence of which the regional unit concerned attains a specific name, social organizations and institutions which are linked with it through their identification apparatus (territorial symbolism), function and/or areas of influence (market areas, for instance). These proportionally serve to strengthen the significance and role of territorial symbols and signs and in this way influence the identity of the region and the potential "feeling of togetherness" amongst its inhabitants.

The identity of some specific region does not normally emerge suddenly, but, being a part of the transformation process of the region, is spread over a long time. It therefore inevitably requires the development of the institutional sphere in the society, in which the region concerned is also institutionally represented. The sphere of institutions undertakes to maintain the process which aims at reproducing the idea of a common consciousness among the people. The reproduction of symbolic dimensions of space consists of the production and consumption of space, which manifest themselves as being interwowen in institutional practices in the field of communication. Signification, domination (command over persons and objects/material phenomena) and legitimation, the structural features implicated in all social systems (see Giddens 1981: 46-48), are also structured into the operation of institutions that are of importance in the reproduction of symbolic dimensions of space. These institutions do not, or course, arise in vacuo. One prerequisite for the increased importance of the Finnish provinces at the end of the 19th century, for instance, was a more effective division of labour, with reflections starting to appear in the spatial structure in the form of features of production (the beginning of centralization and urbanization), 
consumption and exchange (the formation of market areas in particular). This was the functional economic foundation on which the symbolic and ideological organization of space began to arise as a consequence of institutional and individual practices. The background for these developments lay in the changes occurring in legislation in the $1860 \mathrm{~s}$, in that the traditional precepts that had bounded people both socially and spatially to local conditions, were amended in the spirit of liberalism so that labour, in the form of "free workers" was made available for the emerging process of industrialization. The law establishing elemen. tary schools promoted the ability to read and fostered differentation in cultural activities, etc. (Paasi 1984b).

The classical sociologists, especially Emile Durkheim (1893/1964) deliberated profoundly over the effects of the division of labour in societies, which can also be identified in the Finnish case. According to Durkheim, the role of local traditions will diminish during the in creasing division of labour and various general, common, features will gain more room in the consciousness and actions of the members of a society, allowing an organization of people based on rational interests which bring them together. In a society characterized by a division of labour, the role of man's place is also different, since the natural and necessary milieu is no longer that given by birth, but that given by occupation (Durkheim 1964: 182). With regard to the constitution of spatial consciousness, this is the time when - to use a term coined by Erich Fromm -anonymous anthority' comes into play (Fromm 1962). This means that as the division of labour becomes more prevalent, responsibility for communica. tion and control over the socialization process is to an increasing degree transferred from small local communities to anonymous social institutions and the power relations in society become more hidden. Simultaneously local communities disappear or at least lose their crucial role as a fundamental spatial category. The spatial reality surrounding individuals becomes much more extensive (non-local), manifesting itself in the sphere of communication, in the mass media, on the pages of newspapers, textbooks and literature, and in various concrete actions containing a spatial dimension (cf. Habermas 1979: 106-116). Hence it is justifiable to presume that the appearance of an individual/public sphere dichotomy in societies (see Brittan 1977) also has its equivalent in the spatial consciousness of these societies. Or to put it into a historical perspective, where at one time the dialectic between people and history was more locally confined, it is now more and more geographically extensive. This enables the constitution of wider structures of expectations for the regions which may be divorced from the immediate day-to-day lives of individuals, forming an autonomous sphere which exists only through the everyday practices of in. dividuals but cannot be totally reduced to the actions and ideas of single individuals.

The fact that the sphere of institutions is anonymous has important implications as regards the forms of social control and their sedimentation in the reproduction of the structures of signification, domination and legitimation. This sphere constitutes the level of the symbolic environment and meanings that refer to realities other than those of everyday experience (cf. Berger \& Luckmann 1976: 113). It is justified to conceive of the division of labout and the expansion of communication systems as affecting spatial consciousness through various mechanisms and practices, so that this becomes wider and more abstract (cf. time-space convergence). Spatial movement (migration), which is an immediate part of the division of labour, is important for the consciousness of individuals, since it brings the structures of expectations of people living in different cultural backgrounds into confrontation. Nevertheless, if the structures of expectations are already established in society, they do not necessarily disappear, as they represent symbolic dimensions which ultimately reflect the history of the legion, not the interpretations given to them in people's everyday lives.

As noted by Berger and Luckmann (1976: $141)$, ideologies generate solidarity. If the former have counterparts in the functionaleconomical basis of society, the solidarity will presumably be much stronger than if it is founded on nothingness or manifests itself merely in the practices of institutions that continually maintain and reproduce the form and content of (regional) consciousness. In Finland, for instance, several new provinces emerged during the last decades of the 19 th century and achieved territorial symbols and canonized structures of expectations through various economic, political and cultural ac- 
tions. The emergence of the provincial level was closely connected with the rise of nationalism and with the development of the institutional sphere which was to be of greatest importance in the constitution of the idea of a nation-state (Paasi 1984b, 1984c). It is interesting to note that the provincial level of the regional system began to gain in importance simultaneously with the greater prevalence of the new spatial division of labour and its implications (the beginning of urbanization and exchange between centres and rural areas). Since this coincided with the gradual disappearance of the local basis of communities, the latter were in part replaced by larger regional institutions with time-space specific structures of signification and legitimation, the provinces, which became the mediating level in the appearance of a national identity. In a sense the emergence of new Finnish provinces has been something of a paradox. As a consequence of the functional development of society the diminishing role of concrete local communities has been in part taken up by abstract territorial units which manifest themselves mostly in the field of communication, and penetrate the everyday lives of individuals through the agency of institutional practices. Correspondingly, it is apparent that when the structures of expectations are employed for social classification they are an effective vehicle for internal and external social control of the actors in regions, i.e. they offer imaginary reference groups which transcend the differentation in society and its consequences.

The institutionalization of a region is a historically contingent process, which means that once the region receives its status as a part of the regional division of society and an established role in the regional consciousness, it normally turns out to be an institutionalized part of the reproduction and transformation process of that society. The reproduction and transformation of regions is closely connected with political and economic development and their changes in society, since these mechanisms are fundamental to any changes in the regional system (e.g. the emergence of new regions). These material mechanisms can at times manifest themselves in the form of less material phenomena such as culture. In Finnish society, for instance, the recent revival of regional cultural activities is closely connected with regional policy and the economic activation of underdeveloped areas.
Since the institutionalization of a region involves its conceptual and symbolic formation, the most significant institutions in this respect will be those which shape and control the content of the symbolic environment which lies behind our local, day-to-day environment and experience. With regard to nation-states, the most important factor is presumably the formal education supplied by the schools. Education in geography and history in particular is a significant medium for socialization and social reproduction, as these subjects instill in children fundamental notions of the world, the control of space and its historical basis. They give political content to socio-spatial entities and define the major dimensions of "national territories" (see William \& Smith 1983).

The teaching of geography normally produces and reproduces ideas portraying the role of a nation-state in the global system of states, together with ideas concerning the regional system within the state at whose inhabitants this education is directed. In Finland, school geography has been of considerable historical significance as far as the formation of regional consciousness is concerned, as regards both real knowledge and stereotypes (Paasi 1984c). School geography textbooks have been very effective producers and reproducers of the structures of expectations of regions and especially ideas regarding the "character" of other nationalities and people living in different parts of Finland. These characterizations have been instrumental as producers of social classifications. Zacharias Topelius, a patriotic-minded professor of history during the 19th century, canonized the stereotypes for the mentality of the inhabitants of the eight historical provinces of Finland and provided pictures of the physical features and landscapes of these regions in his books, thus laying the foundation for the Finnish people's view of their native country (cf. Mead 1981: 210-211). These descriptions were perpetuated in school geography textbooks up to the 1960 s, together with delineations of the mentalities of other nationalities (Paasi 1984c). It is no exaggeration to assert that every adult in Finland today can outline in a few words the essential stereotype features of the mentality of the inhabitants of at least some of the old Finnish provinces. As regards the regional consciousness of the Finnish people, these portrayals of the character or mentality are among the most essential features in the structures of expecta- 
tions of many Finnish provinces.

During the institutionalization process and emergence of regions nature is normally transformed from being just a basis for material production, exchange and consumption, to a more abstract manifestation in the form of a landscope with a symbolic (aesthetic) role. Landscapes can acquire symbolic values, transcending the day-to-day life of man and concrete processes that mediate the relationship between man and nature: work and its location. This symbolic role is essential for the reproduction of the structures of signification of regions of different size. In Finland, for instance, nature, in the form of landscape is part and parcel of the structures of expectations of several regions and was also of importance in the formation of the idea of the nationstate (Paasi 1984c). Meinig (1979: 164) writes: "Every mature nation has its symbolic landscapes. They are part of the iconography of nationhood, part of the shared set of ideas and memories and feelings which bind a people together". This holds good in the case of Finland, too. The production of an idea of specific (symbolic) Finnish landscapes was significant in the creation of an ideology of nationhood and the nation-state. The role of landscape as a part of the institutionalization process of a region can be canonized along with other signs of the physical world and symbols of the human world to form the structures of expectations of regions.

\section{Excursion: The Finnish case}

What, then, are the important factors in the formation of the collective idea of a region, what factors produce the structures of expectations of regions and graft them onto the everyday life of individuals, transform the regions into "our" places, where "we" feel we belong, distinguishing "us" from "them". As emphasized above, the formal education system is the basis for socialization and also the basis for the functioning of other institutions that reproduce social consciousness (cf. Pred 1983: 51, Thrift 1983: 42). The examples presented below have been of importance historically in Finland.

The mass media of the regions and especially the newspapers, which bear strong economic ties with their market areas, are normally significant for regional consciousness (cf. Thrift 1983). The information that a news- paper transmits consists principally of events taking place in the market area in question and in this way the newspaper limits "our" region very effectively and engenders common experiences. In Finland it seems that stereotypes concerning the mentality of people living in the various provinces are reproduced from one generation to the next through the agency of the provincial newspapers, which have a strong influence on their market areas, since it is usual for over $80 \%$ of the households in a region to subscribe to the most popular newspaper published in that region regardless of its political opinion. A number of provincial newspapers have even formally renounced their political role since World War II for economic reasons, an accentuated regional role naturally being much more effective in marketing the newspaper to all the inhabitants of the region than a political role (connected with some specific party), which is more closely tied to a specific group of inhabitants (cf. Paasi 1984e). Studies on the history of Finnish newspaper's indicate that local newspapers have been crucial for the emergence of a number of new provinces from the end of the 19 th century onwards. Through their market areas, these papers have created a feeling of togetherness, transmitted ideal criteria for regional identification and maintained the elements of the structures of expectations of the regions (Paasi 1984b).

Many geographers have stressed the role of regional literature in the creation of regional consciousness and as a creator and expression of regionalism in different countries (see Morgan 1939, Gilbert 1960, Gilbert \& Litt 1960 , cf. Jensen 1952). Novelists have also influenced the formation of a regional consciousness in Finland at both the national and the provincial level. Literature has been of importance - together with school geography - in the creation of the external and internal identity of regions and hence in mediating structures of expectations. Authors have told to readers how real people (ideal types) living in the regions behave and react in different situations, how their regional consciousness is organized, and what kind of stereotypes they have of themselves and those living in other areas. Novelists have not necessarily aimed at limiting their works explicitly to a given region, but their use of dialects, placenames, etc., have located these works in a specific regional context. This has also served 
to promote a regional classification of the authors and their works in newspapers, for instance. The rapid change in the socio-spatial structure of Finnish society and its consequences (migration, emigration, urbanization) has inspired a revival of regionalistic literature from the 1960s onwards (cf. Paasi 1984d).

As far as the actions of the inhabitants of a given region are concerned, an important occurrence in the institutionalization process is the emergence of organizations and associations which make use of the territorial symbols of the region in their names and actions. The emergence of free associations of inhabitants at the provincial level has been significant for the institutionalization of the provinces in Finland (Halila 1958, Paasi 1984b). Associations like these can have different functions as regards regional consciousness: firstly they can employ as indicators only those symbols of the region which distinguish it from other regions, or at the other extreme work actively to improve the economic and cultural conditions etc. in the region taking the region itself as the principal starting point for organizing such activities (in Finland e.g. Provincial Leagues). The spatial diffusion of the network of associations carrying the name of a given region is a good indicator of the level of regional consciousness. Despite their primarily economic motives, the same can be said of businesses and companies, which employ specific territorial symbolism as an indicator of a common identity and of the limits of their market areas, hence selling their products "in co-operation with space". If their market areas are limited to the region in question, their advertising can of course have a very strong influence on the demarcation of regional consciousness among the inhabitants.

\section{The region as an established part of a regional system and regional consciousness}

The fourth stage in the present framework refers to any continuation of the institutionalization process after the region has achieved an established, although not necessarily administrative, status in the spatial structure of the society and its social consciousness. At this juncture a region also has specific structures of expectations which are constantly being reproduced by social institutions. Assum- ing the institutionalization of regions to be a continuous socio-spatial process, the culmination point and the most formal feature promulgated by the institutions of society is undoubtedly the gaining of an administrative role in the spatial structure of the society, which integrates the region with the general system of public administrational practices. This is not necessarily the most notable or most effective step as regards the social reproduction, however. Although an administrative position establishes the territorial basis for the identity of a region, much more important are the social institutions which are the whole time actively carrying out the reproduction of regional consciousness and impinge upon everyday practices by bringing the region to us, i.e. by communicating information about the area, or maintaining its structures of expectations.

To employ an expression coined by geographers during the $1970 \mathrm{~s}$, the fourth stage of the institutionalization process gives the region an identity which comprises not only a material basis (e.g. nature, landscapes, culture, economic system) but also a "mental sphere", i.e. images which together establish the foundation for the structures of expectations. Hence the fourth stage of the framework is actually a conceptual cross-section of the continuing institutionalization and transformation process in which the region is gradually shaped and reproduced during the development of the society. At this stage the region is also ready to be taken into use as a weapon in ideological struggles, e.g. over resources, power, etc., within society (e.g. in regional policy). As administrative units, regions can also acquire another function from the perspective of power relations, as the material expression of the ends to which state power is applied (Gore 1984: 243).

Regional identity is a concept which is usually associated with the inhabitants of a certain region, and thus, when taken superficially, is analogous to the concept of regional consciousness. In geographical circles this has been expressed in such statements as "A region lives in the mind that is aware of it" (Watson 1971: 31). Nevertheless, if employed more profoundly to denote the essence of the regional system and its development, it cannot be adequately reduced solely to the consciousness of the individuals living in a region. The idea of regional identity has to 
be scrutinized more thoroughly in the perspective and framework presented here, since regional consciousness does not arise from nothing. It may be useful, in fact, to conceptualize it as being an inseparable part of the perpetual process of social reproduction within a given setting.

\section{A framework for conceptualizing "regional identity"}

'Regional identity' is a notion of crucial importance as regards the essence of regions, since it connects both the objective, material (nature, culture, economics) and subjective (individual/collective representations) dimensions of a region. Although the concept has been brought into use in recent years as a part of the geographer's conceptual apparatus, its senses have not been elaborated exhaustively, especially in the context of the emergence and transformation of regions, in other words, in a historical context (see Regional identitet... . 1978, Knight 1982, Paasi 1984a, Wahlström 1984). It would appear that the meanings of 'place identity' have been objects of somewhat deeper consideration in the texts of humanistically oriented geographers, however (see Relph 1976, Buttimer 1978b). In Finland the theme of 'regional identity' has been dealt with in a few explicit studies (Paasi 1984a, 1984b) and, at least implicitly, in the works of sociologists and cultural researchers concerned with the identity of ethnic groups, especially the Swedish-speaking Finns (Liebkind 1984, Lönnqvist 1985).

Regional identity, like place identity, is a theoretical category that mirrors the timespace specific structuration of the multidimensional relationship between individuals and society. In social practice, regional and place identity are realized in different forms depending on the historical, time-space specific, manner in which language and its expressions is used to depict the relationship concerned. Presumably all languages contain emotionally laden words and expressions characterizing the relationship between man and his environment and emotional ties with native localities and a native country. In everyday speech these expressions are manifestations of a man's personal place identity or a more abstract common regional identity, the latter being more explicitly connected with the structures of expectations of regions. A geographer can interpret the time-space specific cultural content of these expressions and their roles in consciousness by setting them in his conceptual framework: i.e. these expressions are manifestations of the concepts of region and place.

As argued above, 'place' is conceived of here in the manner in which humanistic geographers normally comprehend it, as a deeply per'sonal phenomenon founded on one's lifeworld and everyday practices. As Relph (1976: 43) emphasizes, the "basic meaning of place, its essence, does not therefore come from locations, nor from the trivial functions that places serve, nor from the community that occupies it, nor from superficial and mundane experiences, though these are all common and perhaps necessary aspects of places. The essence of places lies in the largely unselfconscious intentionality that defines places as profound centres of human existence"'. As noted above, places are not of necessity confined just to one's everyday environment but also larger spatial units can transform themselves into part of one's place by symbolic means (Tuan 1976). In a humanistic context the meanings of places in this case, too, are structured on the basis of one's lifeworld and its meanings. A region, understood here, quite literally comes to individuals through institutional practices, though the role of region is not inevitably manifested in the lifeworlds of all individuals. Hence the essence and history of a region is connected with the biographies of individuals through the agency of the sphere of institutions, which again is reproduced in the everyday practices of individuals.

Regional identity is a theoretical category which as such is not of much obvious importance for one's everyday life. The concept weaves together elements that are significant in the institutionalization of a region and which are represented in its structures of expectations, while the latter, for their part, operate as a framework for social classification among the inhabitants and those living outside the region. It is nevertheless profitable to isolate some other dimensions from regional identity as well, and the framework presented below is an attempt to conceptualize some of these (Fig. 3). It should be kept in mind that the framework is analytical and thus may contain 


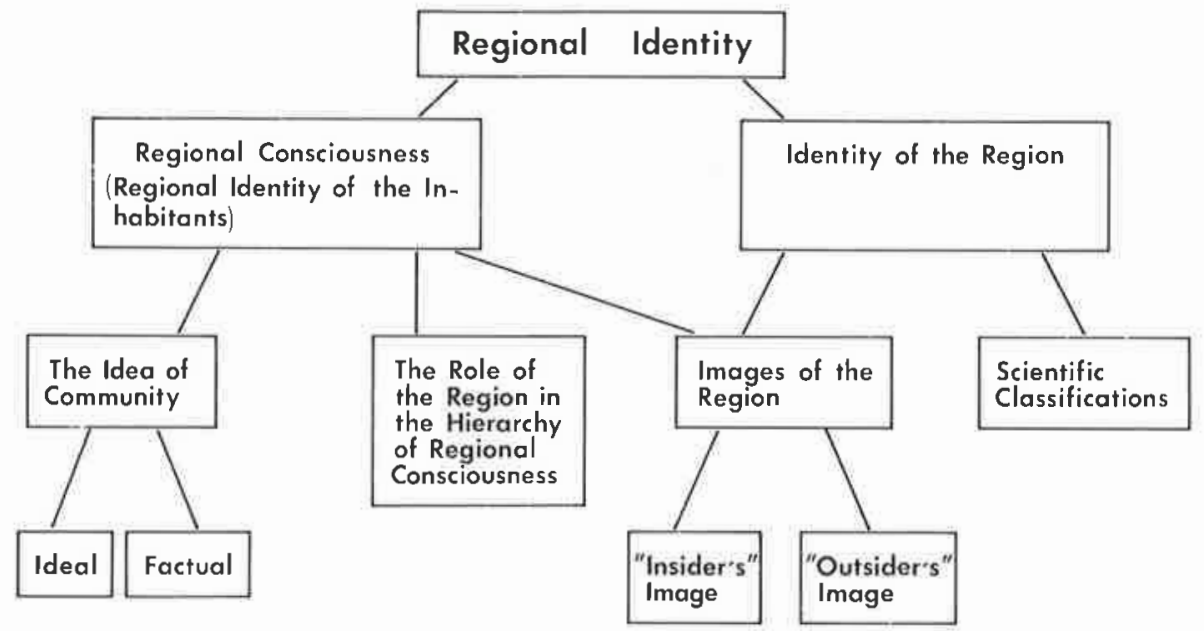

Fig. 3. Some dimensions of regional identity. some logical gaps. This nevertheless does not prevent it from being used as a conceptual instrument, and as such it also seems to be applicable to the empirical analysis of regional identity and consciousness.

The point of departure for the following ideas is that regional identity cannot be reduced only to the regional consciousness of individuals living in a given region. Instead it is more reasonable to base the concept on the institutionalization process, which includes the reproduction of regional consciousness in the inhabitants (and other members of the society living outside the region) and material and symbolic features of the region as parts of ongoing social reproduction. The formation of social identity and the process of social reproduction are, according to Abrams (1982: 262), "one and the same". Accordingly the material and historical basis for the reproduction of regional consciousness is necessarily required in any analysis, since if regional identity were reduced solely to the consciousness of individuals or undefined groups ("communities"), there would not really be very much left over to be analysed. As regards the community character of the concept, the statement concerning the nature of national identity put forward by Gore (1984: 250) also illustrates the content of regional identity: "National identity is a phenomenon of the imagination. It is an attribute of oneself which one imagines one shares with some others and which those others imagine they share with oneself; and it is an attribute which the collective 'we', who have this shared perception, imagine differentiates 'us' from another such collectivity, and which that collective 'they' imagine differentiates 'them' from 'us'. That it is a phenomenon of the imagination does not imply that it is 'unreal'. On the contrary, as Gore goes on to say, it is a significant determinant of human action and is formed through the day-to-day experience and shared memories of people. It is hence sensible to understand regional consciousness as consisting of interwoven cognitive and emotional dimensions as well as that expressing human action. Furthermore, if the institutionalization of a region is neglected when considering the essence of regional identity and consciousness, there would not remain very much substance for apprehending why there exist specific structures of expectations - regional consciousness included - in different regions.

The fundamental distinction in the present framework is between (1) the identity of the region and (2) the regional identity of its inhabitants (cf. Paasi 1984a). By tradition, geographers have made reference to the regional identity of individuals by employing the expression 'regional consciousness', which points to a feeling of togetherness and to the perception of the distinctiveness of their region, manifesting itself in regional contexts of different size (Morgan 1939, Whittlesey 1954, Gilbert 1960, Gilbert \& Litt 1960, Dickinson 1970, Saarinen 1976, Rykiel 1985). Although geographers have worked with the concept of regional consciousness for a long time, hardly 
any thorough-going definitions have been proposed. Nevertheless they have adduced a community basis for regional consciousness, a relationship between regional consciousness and (political) regionalism, the hierarchical nature of regional consciousness, etc., although the essence of this hierarchy has not been elaborated as a social phenomenon, but rather at the level of individuals or undefined regional groups or communities. Geographers have hence not normally aspired to finding an explicit basis for comprehending the essence of regional consciousness starting form the constitution of the regional division of a society as a manifestation of institutional practices, from the emergence of single regions to constitute a part of regional system or from the variable character of the relationship between man and society and the constitution of this relationship at different levels of spatial organization. Analysis of the history of geographical thought indicates that regional consciousness has by and large been comprehended and conceptualized as representing pure 'symbolic values' as such, without any specific social or historical context that would serve to explain its role as a social product and as a part of the social consciousness.

\section{Regional identity of inhabitants}

It is reasonable to divide regional consciousness or the regional identity of inhabitants into two parts: (1) identification with the regional group or community, and (2) the role of a region in the hierarchy of regional consciousness, i.e. identification with a specific region. The former refers to those inhabitants of a region who have a more or less clear opinion of their "own" regional group in which they feel that they belong. The arguments for the feeling of togetherness can vary a lot, which points to the fact that (2) human beings live simultaneously within numerous territorial units having variable meanings for them and being symbolized differently depending on their role and importance for the institutional practices of the society (cf. Knight 1982, 1983). The larger the region is, the more complex and symbolized its meanings normally have to be. It is abundantly clear that the structures of expectations of regions are also structured hierarchically, and that their content varies with regard to different regional levels, starting from immediate personal environments and proceeding up to nationstates and finally the global reality.

\section{On the nature of regional communities}

A community is generally regarded as an ideal form of existence for man. As Bell and Newby (1973: 3) put it, "most definitions of community reflect not so much what community is but what it should be. Normative prescription has overridden empirical description in most cases" (cf. Calhoun 1980). When the role of the spatial dimension in the constitution of communities is specified, i.e. the nature of regional communities is deliberated, it is justified to make a distinction between locally controlled communities with high presence availability (face-to-face communities), or factual communities, and those which are represented and communicated to the everyday life of individuals as an ideal state of affairs by means of the practices of non-locally controlled institutions, e.g. in the shape of an abstract "we-feeling",

Hence identification with a community can also be divided into two levels, factual and ideal identification. The former points to actual (usually face-to-face) relationships between individuals, which are connected with a region in some manner (participation in regional associations, actions in which a region is present in the form of a non-problematic "common" cultural basis for action involving people speaking the same language or dialect, for instance, or people having the same structures of expectations regarding the structure of space-time). The role of this everyday cultural community obviously emerges in cases of migration, when people are confronted with new structures of expectations whicli demand an acculturation process.

Ideal identification refers to the 'picture' of identification communicated by and represented in the institutional practices of the region and society in question. This is certainly essential with regard to the socialization and reproduction of consciousness, but it does not tell us in any way how individuals really identify themselves with others living in a region that is held by public opinion, e.g. in the press, to form a community. In this case an illustrative concept, written identity, can be adopted (see Lönnqvist 1985). This manifests 
itself typically in the speeches of regional activists, or on the pages of regional newspapers, novels, etc., reflecting the ideal identity that is arranged into the structures of expectations of the region concerned. It is commonly represented as giving an impression of the existence of a kind of regional solidarity among individuals. It is in part similar to what Habermas (1979: 95-129) calls collective identity. He reserves the expression for reference groups that can be essential to the identity of their members, groups which are in a certain sense 'ascribed' to individuals and cannot be freely chosen by them, and which have a continuity that extends beyond the life-history perspectives of their members. People are born into these groups and the field of communication mediated by the institutions of the region and society.

In the case of newspapers, for instance, "Gemainschaft" language, expressions comprising an idea of regional solidarity, typically reflect the fundamental social function of the mass media, i.e. efforts to create common social values and even a time-space specific social reality, and also, from the economic point of view, a desire to increase the distribution area of the newspaper. One concrete basis for such writing in Finland, for instance, has been the uneven pattern of regional development, which has given rise to a completely new regionalistic terminology in the pages of the newspapers of underdeveloped areas over the last 20 years or so (Paasi 1984e). It has been quite typical in the public opinions as expressed by the newspapers for problematic economic and political controversies to be reduced to a myth that areas interact and exploit each other and not economic relations or political decision-making (cf. Gregory 1978: 120, Urry 1981). As seen above, neoregionalistic terminology has also become quite popular in Finnish literature (novels, pamphlets).

One historically important idea connected with regional identification in Finland has been the discussion of regional spirit and a historical feeling of togetherness among the inhabitants of given regions. The former concept originates from the end of the 19th century and was presumably originally introduced by the primarily regionally-based Student Unions at the University of Helsinki at a time when a provincial way of thinking in general was becoming more popular in Finnish society. Finnish politicians and civil servants have continually employed the expression "historical feeling of togetherness" as an important argument in official committee reports when planning revisions of existing regional divisions - even though the number of regions and their form and size may vary greatly in their plans (Paasi 1984b). This clearly indicates that we are speaking of an ideal identity or community, since it manifests itself at the level of the institutional sphere and can change when needed.

Classification systems in a society are social products and manifestations of power relations (cf. Bourdieu 1985a: 89). Sociologists and cultural researchers point out that the definitions of ethnic groups, for instance, are social processes, and that the prerequisite for a group to emerge is that someone (institutions /individuals) should draft and finally canonize the demarcations (Paasi 1984a: 59-73). At the beginning of the institutionalization process the role of single persons (regional activists) can be considerable in establishing these demarcations (as has been in the case with the new Finnish provinces) but in the long run it is the anonymous, regionally based institutions responsible for socialization in society that carry most weight. Nevertheless, socialization normally presupposes that the regions already have an established institutional position in the regional system and consciousness. Whether it is a matter of single regional activists or institutions, the role of economic, political and cultural elites is, and has always been, crucial in mediating between the consciousness of inhabitants and the society at large.

The point of departure for the formation of ethnic groups is generally the specific social group with its social situation. If the "region" is the only essential basis for a community to emerge, the role of external classifications those not emerging from the socio-economic and historical situation of the group itself will presumably be much more significant. This inevitably underlines the significance of institutional practices and their role as a medium of social control and power (cf. Pred 1981c, 1984a). Common experiences in everyday life and involvement into common meanings and symbols are essential preconditions for the emergence of a local collective identity. Conversely, common experiences and involvement in common meanings and symbols that do not rise from the experiences of day-today practices and the environments of in- 
dividuals living somewhere at some moment of time offer a possibility for the existence of a regional consciousness or regional identity among the inhabitants of a given region most of them unknown to each other. The latter, as an institutionally maintained collective tradition is more connected with the history and characteristics of the region than with its individual inhabitants.

If the problem of the regional community is approached more analytically, and also somewhat more technically, by employing the conceptual distinction between place and region as a point of departure, some substance could perhaps be found to facilitate an understanding of the formation of a regional community and the establishment of the idea of community as one part of the structures of expectations attached to regions. The establishment of a "we" and "they" distinction is based on actions taking place in the sphere of institutions, which identifies, signifies, legitimates and finally maintains, reproduces and sanctions the community idea in a given region. As regards a place, on the other hand, "community is involvement in the sense of a projection of oneself on to the so-called objects of one's concerns" (Samuels 1971: 214). Thus, Samuels (1971: 215) goes on, "there are, then, no objective communities in the world, but rather some three billion and more communities, each with someone at their respective cores". Consequently, by employing technical sociological terminology to define a community, a region becomes a reference group, in which the idea of community, produced and reproduced by the practices of institutions, is much more substantial than the relations between single individuals conceived of as its members. The place, adequately, is a primary group in which one's meaningful social relations are constituted on the basis of one's day-to-day practices in an everyday environment (cf. Calhoun 1980). In this sense a community consists of common path-elements in the intercourse of individuals, in which the personal meanings attuned to the elements are of special importance.

The problem of regional identification and the nature of a regional community has been dealt with or at least touched upon in the course of geographical thought inasmuch as the idea of region has at times been conceived as arising precisely from the intimate relation- ship between the inhabitants and their region. A region has occasionally been comprehended as an area of common living, or especially in the classical tradition of French geography, as a scene where the relationship between man and the environment engenders certain timespace specific styles of living or genres de vie (see Buttimer 1971, 1978a). Paul Vidal de la Blache's ideas of genre de vie, for instance, emerged from rural society and the idea of community consciousness came into being from this source. Buttimer (1968: 136) writes that "Repeated experiences in meeting life's common problems within a particular geographical milieu occasioned the development of community consciousness which made genre de vie truly an ecological system". If one presumes that personal, spontaneous faceto-face interaction between the residents of a locally-based community can give rise to a sense of community and accordingly engender common structures of expectations, in other words, the criteria defining the nature of a community do not come from outside the community, as an expression of the action of non-locally-based institutions, the community concerned cannot be very large. The modern division of labour in particular is notorious for crushing the foundations of regional communities since different consequences and actions originating from the division of labour are now the ultimate basis for the constitution of different groups or communities. The spatial setting in which this action takes place is obviously of minor importance. Hence in modern societies it is not the spatial structure of reality itself that gives rise to communities, although a spatial dimension is present in all communities. A community always has territorial ties, yet the boundaries of the territories have to be determined inside or outside the community. A territory is therefore always a tool for social classification, reflecting economic, cultural, political and other interests that manifest themselves through the practices of institutions, which are for their part essential in the reproduction of regions and their role in consciousness.

Buttimer (1971: 52) adduces that the geographers of the Vidalian tradition were driven to sociological naiveté. Vidal himself, for instance, tended "to treat social groups as monolithic entities, whose external relations and collective response to environment were more important than their internal structural 
or qualitative characteristics" (Buttimer 1971). As Buttimer's monographe indicates, the idea of the (collective) subjective dimension of regions has occupied a prominent position in the tradition of French geography, and its role has also been noted in the traditions of British, German and North American geography (Paasi 1983).

Recent discussions of the nature of genre de vie appear to concentrate more explicitly on the relationship between local environments and (small) groups. Buttimer (1978a, 1979), for instance, considers the role of groups in modern cities. Of special interest for the present study are the articles by Pred (1981b, 1984a) in which he endeavours to elaborate the concept of genre de vie from the angle of the theory of structuration, establishing the former as a coherent part of the totality of the latter. Pred does not explicitly consider the role of this framework from the standpoint of socio-spatial structure and its regional levels, and he refers to the demarcation of regions only when stating that in his framework the societal institutions and organizations (and their elites) that set authority constraints and define local projects (and independently existing roles) may be based either inside or beyond the place or area in question (Pred 1981b: 247-248). As for the essence of communities, it is essential to explicate the possibilities and limitations of the "community" or group whose genre de vie is discussed. When considering the concept of "sense of community", for instance, it is of great importance to assess the roles of "ideal" and "factual" aspects in its constitution. Furthermore it is presumably essential to consider to what extent it is the spatial and the social dimensions of reality that shape the features of genre de vie. The two dimensions of course form an interwoven process and hence it is abundantly clear that they cannot be discussed without each other. The concept process in connection with a region or territory serves to draw our attention to the transformation of the socio-spatial complex whose genre de vie is being considered.

Altogether, if emphasis is placed on the point that the abstraction of place is realized in the jungle of personal paths and projects and in the meanings given to them, in spite of the fact that social reproduction occurs precisely through these, the region is not an immediate part of the day-to-day practices of people living in it, but is rather the product of encounters between the paths and projects of individuals and institutions. Hence it is again essential to problematize the role of institutionally mediated social structures as directors of regional consciousness and consider what are the essential features of the logic according to which the institutional practices (within the spheres of economics, politics, legislation, etc.) and their manifestations in the structures of signification, domination and legitimation, penetrate and colonize the spatiality of local day-to-day life through the agency of non-local collective meanings at the same time as the structures referred to are continually being reproduced in individual practices. In consequence an important problem concerns the factors influencing the emergence and transformation of the community. With regard to concrete studies, it is presumably reasonable to make both an empirical and a conceptual distinction between ideal and real (factual) communities and their origins in the institutional sphere of the society, so as not to take the idea of community for granted or as a normative category.

\section{Identity of a region}

The identity of a region can also be divided into two parts, "subjective" and "objective". The former refers to images held by (1) the inhabitants and (2) those living outside the region. These images can also be apprehended as being part of regional consciousness. The latter points here to classifications constructed within different scientific disciplines, for instance, i.e. regional divisions based on the physical environment, culture, landscapes, etc. The single regions in such divisions can be understood as having an identity of their own which distinguishes them from others. This (usually) static, researcher centred, identity is as a matter of fact one of the traditional geographical definitions of region, i.e. region as a mental category for classification. The use of the word "objective" in this context hence implies not an ontological attitude towards the essence of regions, but rather that regions in different divisions are in certain respects objective, if they have been made up by objective criteria, the choice of which, of course, is normally a more or less subjective procedure 
determined by the research problems concerned. Nevertheless, as far as the transformation of the spatial structure of society is concerned, these regions are not necessarily objective unless they reveal the constitution of a dynamic relationship between society and its spatial structure. Hence it is to be emphasized that individual regions in regional divisions are no more than one part of the framework introduced in the present study in order to comprehend the essence of regions, and that especially with regard to the institutionalization of regions in society, defining a region merely as an apparatus of classification neglects the relationship between 'social' and 'spatial', the central foundation for social reproduction.

The internal ("insider"s") and external ("outsider's") images of a region are an essential part of its identity, and the concept of structures of expectations appears to be especially profitable for understanding these. Images make up one part of the dynamic process of continuity that is the region. As proposed above, the relationship between structures of expectations and regions is not constant, and it is customary for the former to be strongly directed towards the past of the region, as it were, emphasizing its historical features, which live today in reproduced form mainly in the sphere of institutions, whereas the latter are constantly being directed towards becoming. The historical accumulation of knowledge of course perpetually affects the content of structures of expectations, inasmuch as regions are subject to a continual transformation process. Structures of expectations can therefore also involve at times elements that seem not to originate from (or belong to) the region concerned.

The role of outer and inner images is different in social practice. The outer image of a region is its "poster" in social consciousness and can be manipulated by the institutional sphere. Landscape is normally essential in the image of a region. In Finland, for instance, landscapes and nature in general are the most significant features that the Finns use as arguments when classifying Finnish regions e.g. in space preference studies, although collective cultural, physical or landscape features transcending one's day-to-day living environment are less important in one's own identification with regions (Paasi 1984b). As far as tourism is concerned, for instance, certain features of the structures of expectations can be emphasized more than some other to form a portrayal of a given region which is as enticing and exciting as possible. Similarly the images of regions where riots, war, hunger, etc., are an essential part of people's everyday practices can also be manipulated. In spite of the possibility of manipulation, the most essential features of the structures of expectations are usually quite permanent, inasmuch as the history of the region has an essential role in them. The inner image of a region comprises the idea of $d e$ marcation of the inhabitants and other features of the region from others. Inner images are in the first place instruments for the territorial classification of the features of sociospatial reality. This involves explicitly a consciousness of the special character of one's "own", or "our" region, and what factors it is based on. Images portray a physical and social reality which is normally mainly beyond one's local day-to-day life, and it is these and the facts, stereotypes and myths in them that constitute the spatial basis for our view of the world. In this respect it is evident that both inner and outer images of regions offer a significant medium for social control and manipulation (cf. Paasi 1984a, 1984c).

Geographers have dealt with the problem of regional images when discussing the ontological nature of regions in their methodological discourses. Holistic ideas related to the essence of regions have at times included mystical overtones concerning the "soul" or "spirit" of a region, for instance. The "Gestalt" terminology employed by some German Landschaft geographers early in the present century comprised an unparalleled number of ambiguous expressions, culminating in deliberations on German "Lebensraum" (see Schultz 1980, Paasi 1983). As the study of Buttimer (1971) indicates, ideas which concentrate on the organic and psychological connection between regions and their inhabitants were also included in the works of some representatives of French geography (cf. also Buttimer 1968). The crucial problem in geographical argumentation over "psychic wholes", "Gestalt", "regional character", etc., has unmistakably been that the relationship between regions and their inhabitants has been reduced ultimately to a psychological problem, not a manifestation of the perpetual reproduction of regional consciousness generated by the institutional practices of 
society, nor an expression of the structural relations in society which aim at the continual controlling and creating of social space.

In the history of geographical thought the "Gestalt" has at times been apprehended as an image that is structured into one's mind after one has been in intimate contact with a region for long enough. It is an image that is conceived of as being constructed personally through the relation between a person and region. Cahnmann (1944, cf. Wörner 1938), for instance, writes: ". . . if we speak about Alpenlandschaft, paysage Mediterranien, the landscapes of Manhattan or the Mississippi Delta, we refer to an ideal type or, in other words, to a Gestalt or psychic "Whole" which exists in the mind of a student who has lived and worked in a region so intensively that he has come to experience the region, as it were, in a most intimate way" (cf. also the discussion regions as gestalten by Kirk 1963, and the reference to region as a subjective Gestalt by Pocock \& Hudson, 1978: 7). Especially historically oriented geographers have for a long time taken a special interest in the subjective dimension of the man-environment relationship (see the seminal articles by Wright 1947 , Clark 1950: 20-21, Kirk 1951, 1963, and Lowenthal 1961). A comprehension of the nature of the transformation of a region to a "Gestalt", is a prerequisite for apprehending the mechanisms that lead to the depiction of a given region as an entity in the minds of individuals. This inevitably calls for an analysis of the socio-spatial structuration of regions and their historical formulation as a background for studies on "Gestalt".

The problem of methodological individualism or psychologism is also present in modern geography, where particularly behavioural geographers frequently accept, at least implicitly, the principle of methodological individualism in their preference and image studies founded on survey methods. Normally the responses are explained by employing the characteristics of the respondents (sex, age, socio-economic position, etc.) as the only variables. The structural features sedimented in the socio-spatial transformation of society, the real basis for comprehending the existence of given structures of expectations, manifesting themselves in the images of inhabitants, have not by tradition been objects of study.

The use of the concept of regional consciousness can easily steer scientific work towards normative and uncritical notions if it is taken for granted, ahistorically or as a normative, idealistic statement of regional "spirit", "soul", etc. This is not necessary, however, if the notion is apprehended as a product of institutionally mediated practices in society. It is beyond dispute that with regard to different regional levels, the nature of a potential commune is different (cf. Thrift 1983: 47), the institutions and organizations which create solidarity in a region (and the motives of their elites) may be transformed, the level of abstraction of regional communities may vary and the role of regional consciousness in the inhabitants' concrete actions may alter (10). Thus it is evident that these problems can be analysed most profoundly by employing an approach that identifies a region (and regional consciousness as a part of it) as a socio-spatial category whose development can be comprehended only as a part of the development of the society in question and its spatial structure.

\section{Epilogue}

The aim of this work has been to discuss a framework which facilitates an understanding of the nature of regions and their evolution as human and social institutions. Thus, instead of trying to present an exact definition of the concept of region, the purpose has been to decompose the concept of region analytically into pieces which characterize its historical and social nature from different perspectives. After analysing the meanings of regions from the perspective of the history of geographical thought, the point of departure has been to conceptualize the region as an institutionally mediated sphere of society. Hence both a region and its structures of expectations are in perpetual movement along with society itself. The purpose has not been to begin from the region itself, neither as a concept nor even as a static level in a concrete society, but from the relationship between the institutional sphere of society and the individuals, as this relationship forms the fundamental meeting place where society, social consciousness, and as a part of the latter, regional consciousness are continually reproduced. Hence regions are essential parts of the socio-spatial structure of a society, where the role of single regions can 
vary from pure ideas to administrative functions.

Structures of expectations form an important category which facilitates comprehension of the role of regions in social classification and in classifications based on physical and cultural features of reality. When the concept is connected with time-space relations in concrete situations, it can be employed in the analysis of the hierarchical nature of spatial consciousness. In geographical work, and especially in regional geography, an understanding of the perpetual reproduction of structures of expectations is a prerequisite for any analysis of the historical process that has produced the regions and regional consciousness. Appreciation of the existence of structures from one generation to another, on the other hand, requires identification of the sphere of institutions which continually reproduces and mediates these structures and also modifies them in the course of the development of the society concerned.

The acceptance of regions as historically continuous processes facilitates an understanding of the identity of the regions in question. The very concept of regional identity is a complex expression of the development of the society and its spatial structure, and in order to understand its different meanings, a processual perspective is again needed. Regional identity integrates the material phenomena of the regions with the ideas of the regional community formed by the inhabitants, the images of the region and the structures of expectations.

As far as the basic categories of geographical thought, place and region, are concerned, it appears to be useful to make a distinction between these, based on their relationship to the everyday practices and experiences of individuals. The concept of place expresses the structuration processes through which the everyday practices of individuals and institutional power relations emerge out of each other, in addition to which the essence of place lies in the meanings that individuals associate with their physical, cultural and social environments. The region, on the other hand, is an entity that cannot be experienced directly, but is represented in the everyday lives of individuals by symbolic means through political, economic, legal and other institutions and the power relations associated with them. The structures of expectations of regions that individuals employ in social classification consist of elements that reflect the life and history of the region as a symbolic entity, not those of individuals. In this respect the regions contain an explicit collective dimension which has relative independence, being continually reproduced by institutionally embedded power relations that influence the socialization of individuals.

\section{NOTES}

1. On trends and approaches in historical geography, see Clark (1954), Smith (1965), Guelke (1982), Butlin (1982) and articles in Baker \& Billinge (1982).

2. In sociological terminology, institutions normally refer to standardised, quite permanent modes of behaviour which are controlled by expectations connected with various roles (cf. Giddens 1979: 96). The sphere of institutions usually refers in the present study to cultural, economic or political institutions etc., that have an explicit or implicit spatial dimension in their actions, or more specifically are concentrated on the production and reproduction of the regions and regional consciousness in society. It should be recognized that social institutions do not act behind the backs of individuals, but instead individuals create and reproduce these institutions actively in the practices of their everyday lives. As Giddens
(1979) notes, every capable member of a given society knows quite a lot about its institutions. Nevertheless, the logic of the history of institutions does not inevitably manifest itself explicitly in the routines of one's everyday life. Hence their social funtion will become partly unconsciously established in the routines of day-to-day practices of individuals. This has become more apparent during the increasing division of labour in society, which has reduced the role of old, traditional and local commumities in socialization and replaced them to a great extent with indirect social communication.

3. The problem under discussion, i.e. the emergence of some specific region, must not detract from the fact that the spatial structure (of global reality) manifests itself continually in the form of several hierarchical regional levels as well as a medium through which more complicated socio- 
spatial relations are continuously produced and reproduced. The emergence of a region in society is a consequence of natural, cultural, economic and political processes, mediated socially and spatially. In this respect "regions" as such are always abstracted out of the whole spatial structure.

4. The present theme implies several problems that are present in geographical studies concentrating on the nature of social space, its constitution and the distinction between its subjective/objective dimensions or their inseparability. Of special interest are the discussions concerning the constitution of the symbolic dimensions of space by humanistically oriented geographers (see Buttimer 1969, 1976, 1979, Tuan 1977). Harvey (1970) in particular lays stress on the relationship between social processes and spatial form. In the present study 'social' and 'spatial' are understood as forming an intertwined process which manifests itself in different institutions and structures of society, of which the "regions" are of special interest for this work. As regards the regions, the discussion of Buttimer (1979) on 'insider' and 'outsider' perspectives in regional geography touches upon the problems set forth in the present work, although Buttimer does not touch upon the relationship between "my" region and "ours" (i.e. the nature of regional communities), which is the essential point of departure for the present study, since this relationship forms the mediating level at which the spheres of institutions and individuals coincide.

5. "Sense of place", "place identity", etc., have been among the most popular concepts that humanistically oriented geographers have employed since the mid-1970s (see Relph 1976, Tuan 1977, Buttimer 1978). These concepts portray the relationship between man and his place and the dimensions of experience that are essential in the constitution of one's place. The emphasis has been on values, meanings, consciousness, creativity and other dimensions which have been regarded as being of importance for the everyday life of individuals. Criticism of the humanistic perspective has been directed at the lack of a social dimension in such works of humanistic geographers. Ley (1980, 1981), for instance, speaks of the potential danger of erring towards voluntarism and idealism, a criticism which is typically connected with the works of humanists (see Cosgrove 1978, Sayer 1979, Cox 1981). The central problem between the ideas of humanistically oriented geographers and their critics is the problem of the irreconcilable images of man: the viewpoint according to which the essence of man is in his existence and the other extreme which regards the essence of man as lying beyond the individual, in the cultural totality produced in the course of man's history (see the problems discussed in Ley 1982 and Gregory 1982b). Although the images of man are arguable and in a way contradictory, this is no reason for a geographer to abandon one or other of these. When man's spatial existence and his role as a member of different groups, classes and the whole of society is to be discussed neither of these viewpoints can be automatically abandoned. For individuals the spatiality of everyday life, manifested in their relationships with environments, landscapes, etc., is the only context for understanding and interpreting the Geographical World. As far as their role as members of groups or a society is concerned, the role of institutions (political, economic, administrative, cultural, etc.) as mediators of the structures of society turns out to be of importance as an object of study. The present work approaches the problem of these conflicting images of man both logically and historically. The aim is to conceptualize the historical and social process producing the time-space specific entities which a geographer terms places and regions.

6. Giddens (1979: 225-230) discusses the processes of change taking place in modern societies and emphasizes the significance of uneven development for understanding the tendencies manifesting themselves in time-space relations between nation-states and within them. Uneven development implies differential rates of change in political and economic forms and their location in different regions. In the current historical situation he perceives three basic dimensions in which conflicts and attachments are crystallized, class, ethnic differentation and territorial claims, which all tend to be regionalized in time and space (cf. Gore 1984: 262). As far as regions are concerned, the question of territorial interests (and implicitly also the question of the nature of a territorial community) is of importance. In connection with regionalism it is to be noted that the problem of concrete and, at the other extreme, ideological interests is a hierarchical one. Also the nature of interests and the mechanisms that maintain and reproduce the idea of their existence differ at each regional level (the relationship between individuals, or groups, and their everyday environment, a region or nationstate, for instance). It appears to be that defining time-space specific territorial interests and their role as regards the whole spatial structure of society is not an easy task, inasmuch as the definitions depend radically on the motives and interests of those responsible for them (see Gore 1984: 225229).

7. Pred (1983: 55, cf. Thrift \& Pred 1981) uses the concept of "structure of feeling" at the level of places and regards it as conceptually superior to most versions of sense of place, discussed by humanistic geographers, because structure of feeling more explicitly acknowledges the impact of social and historical context on individual experience. According to Pred, an individual acquires a structure of feeling partly by "having her path exposed to news of particular political-historical events by word-of mouth, the printed words, or the modern media, partly by the everyday intersection 
of her path with time-space specific institutional projects which also require both the path intersections of other persons (...) and common interaction with objects (...); and partly by the constraints and possibilities imposed on her other forms of project participation, and thereby knowing, by fixed commitments to dominant institutional projects" (Pred 1983: 56).

8. The structures of expectations attached to regions are not mystical cultural "superorganis" operating as autonomous forces above individuals. This has been at the core of the criticism of cultural geography and the concept of culture presented by Carl O. Sauer, for instance (see Duncan 1980). According to Sauer (1941: 356), "Human geography, then, unlike psychology and history, is a science that has nothing to do with individuals but only with human institutions, or cultures". The point of departure for the present study is that culture is not apart from individuals, but acquires its content through and is realized and reproduced in the everyday practices and routines of human beings, in the subjective actions and objective conditions (their position in the division of labour and its implications) of their way of life (cf. Williams' 1961: 41, definitions of culture). In a way, these objective and subjective individual and collective dimensions of everyday life are interconnected precisely through action. Structures of expectations form a concept that describes the relationship between individuals and society as a spatial dimension of social reproduction. It is a structural concept inasmuch as it cannot be totally reduced to the consciousness and ideas of individuals concerning their own regional existence, and it bears with it the historical role of the region in the spatial organization of the society. Of course it exists only through the individuals and through the material and intellectual phenomena of the society. Individuals are not just passively introducing their regional "self-consciousness" but can and do actively shape it within the limits they have in the jungle of the institutions, organizations and division of labour within the society. The development and roles of institutions are not results of autonomous forces but follow from the purposes and decisions of the elites that control and direct the sphere of institutions (see Pred 1981c, 1984a).

9. Since the present research project is aimed at analysing the institutionalization of four Finnish provinces, most of the empirical illustrations are based on the development of the Finnish spatial reality and Finnish regional system, which consists today of 12 administrative provinces (läiani) and some 460 communes (kunta). As far as the regional consciousness of Finnish people is concerned, historically the most significant regional unit appears to be the maakunta, a province in the proper, even Royce'an sense of the word (Paasi 1984b). A mactkunta is comprehended in the Finnish regional consciousness as the fundamental level for the feeling of togetherness, although this division became important only from the end of the 19th century onwards. Administrative provinces (lääni) are often regarded as manifestations of the centralizing tendencies of the state, rather than the communities that the maakunta are often held to be, in spite of the fact that their areas coincide in most cases nowadays! This clearly reveals that the makunta is perceived as an ideal community, a fact which is reflected in Finland today in a continuing tendency to adopt new tersitorial symbols for provinces (provincial birds, flowers, etc.) alongside the older one (provincial coats of arms, songs, etc.). This state of affairs is continually being strengthened by the institutions acting at this regional level, the most important of which are the provincial newspapers.

10. An interesting concept expressing the hierarchical nature of the organization of physical manifestations of norms, laws and other time-space bounded aspects of authority is that of domain or control area, coined by Hägerstrand (1970, cf. Carlstein 1982: 45). According to Hägerstrand, smaller domains are protected only through immediate power or custom (e.g. favourite chairs, a sandy cave on the beach, or a place in a queue), whereas others can have a very strong legal status and long, even permanent duration. The idea of domain also penetrates the distinction between the concepts of place and region. At the place level, domains are immediate dimensions of the organization of the everyday practices of individuals and reflect the capabilities of individuals to act in the jungle of constraints. In the sphere of regions, domains are more explicitly institutional manifestations of the historical organization of the power relations of the society.

When analysing the works of time-geographers, Giddens (1984: 115-126) replace the concept domain with the expression "regionalization" (of time-space) which points "to the movement of life paths through settings in interaction that have various forms of spatial demarcation". Regionalization thus refers not only to localization in space but also to the zoning of time-space in relation to routinized social practices.

\section{ACKNOWLEDGEMENTS}

I arr greatly indebted to Professor Allan Pred for kindly reading the manuscript and for a day's detailed discussion in Stockholm on the topics dealt with here, which clarified the conceptual frame considerably. Particular thanks are also due to Academician, Professor Olavi Granö for many fruitful discussions on the theme and the history of geography in general. I also wish to thank him, together with Docent Arvo Peltonen, Dr. Roger Anderson, and, at the University of Joensuu, 
Professor Juhani Hult, Dr. Pauli Karjalainen, and Dr. Perttu Vartiainen, for reading the manuscript and making comments from which I have benefitted greatly. The final product is nevertheless naturally my own responsibility! I am also indebted to Mr. Malcolm Hicks, M.A., for checking the English of the manuscript. Finally I acknowledge with gratitude the financial support received from the Academy of Finland which has made this project possible.

\section{REFERENCES}

Abrams, Philip (1982). Historical Sociology. 353 pp Pitman Press, Bath.

Baker, Alan R.H. \& Mark Billinge (eds. 1982). Period and Place. Research Methods in Historical Geography. 377 pp. University Press, Cambridge.

Bell, Colin \& Howard Newby (eds. 1974). The Sociology of Community. A Selection of Readings. $355 \mathrm{pp}$. Cass and co., London.

Berger, Peter \& Thomas Luckmann (1976). The Social Construction of Reality. A Treatise in the Sociology of Knowledge. 249 pp. Penquin Books, Harmondsworth.

Bergsten, Karl Erik (1954). Den geografiska regionen. Svensk Geografisk Årsbok 30, 63-74.

Billinge, Mark (1981). Place. In Johnston, R.J. (ed.): The Dictionary of Human Geography, 254. Basil Blackwell, Oxford.

Bourdieu, Pierre (1977). Outline of a Theory of Practice. 248 pp. Cambridge University Press, Cambridge.

Bourdieu, Pierre (1985a). Sosiologian kysymyksiä (Orig. Questions de sosiologie, 1979). 224 pp. Vastapaino, Jyväskylä.

Bourdieu, Pierre (1985b). The social space and the genesis of groups. Theory and Society 14, 723744.

Bourdieu, Pierre \& Jean-Claude Passeron (1977). Reproduction in Education, Society and Culture. 254 pp. Sage Publications, London.

Brittan, Arthur (1977). The Privatized World. 184 pp. Routledge \& Kegan Paul, London.

Butlin, R.A. (1982). The Transformation of Rural England s. 1580-1800. A Study in Historical Geography. 64 pp. Oxford University Press, Bristol.

Buttimer, Anne (1968). Social geography. In Sills, David L. (ed.): International Encyclopedia of the Social Sciences, vol. 5, 134-145.

Buttimer, Anne (1971). Society and Milieu in the French Geographic Tradition. 226 pp. Rand McNally, Chicago.

Buttimer, Anne (1976). Grasping the dynamism of lifeworld. Annals of the Association of American Geographers 66, 277-292.

Buttimer, Anne (1978a). Charism and context: the challenge of la geographie humaine. In Ley, David \& Marwyn Samuels (eds.): Humanistic Geography: Prospects and Problems, 58-76. Maaroufa, Chicago.
Buttimer, Anne (1978b). Home, reach and the sense of place. In Regional identitet och förändring i den regionala samverkans samhälle, 13-39. Acta Universitatis Uppsaliensis 11.

Buttimer, Anne (1979). 'Insiders', 'outsiders' and the geography of regional life. In Kuklinski, Antoni, Kultalahti, Olli \& Briitta Koskiaho (eds.): Regional Dynamics of Socioeconomic Change, 155-178. Finnpublishers, Tampere.

Calhoun, C.J. (1980). Community: toward a variable conceptualization for comparative research. Social History 5, 105-129.

Cahnmann, Werner (1944). The concept of Raum and the theory of regionalism. American Sociological Review 9, 455-462.

Carlstein, Tommy (1981). The sociology of structuration in time and space: a time-geographic assessment of Giddens's theory. Svensk Geografisk Arsbok 57, 41-- 57.

Carlstein, Tommy (1982). Time resources, society and ecology: on the capacity for human interaction in space and time in preindustrial societies. Lund Studies in Geography, Ser. B, Human Geography No. 49. 444 pp.

Clark, K.G.T. (1950). Certain underpinnings of our arguments in human geography. Transactions of the Institute of British Geographers 16, 1522.

Clark, Andrew (1954). Historical geography. In James, Preston \& Clarence Jones (eds.): American Geography, Inventory and Prospect, 70105. Syracuse University Press.

Cosgrove, Denis (1978). Place, landscape and the dialectics of cultural geography. Canadian Geographer 22, 66-72.

Cox, Kevin (1981). Bourgeois thought and the behavioural geography debate. In Cox Kevin \& Reginald Golledge (eds.): Behavioral Problems in Geography Revisited, 256-279. Methuen, London.

Dickinson, Robert (1964). City and Region. A Geographical Interpretation. 588 pp. Routledge \& Kegan Paul, London.

Dickinson, Robert (1970). Regional Ecology. The Study of Man's Environment. 199 pp. John Wiley, New York.

Duncan, James (1980). The superorganic in American cultural geography. Annals of the Association of American Geographers 70, 181-198.

Durkheim, Emile (1893/1964). The Division of 
Labour in Society. 439 pp. Free Press, New York.

Entrikin, J. Nicholas (1981a). Royce's provincialism: a metaphysician's social geography. In Stoddart, D.R. (ed.): Geography, Ideology and Social Concern, 208-226. Basil Blackwell, Oxford.

Entrikin, J. Nicholas (1981b). Philosophical issues in the scientific study of regions. In Herbert, D.T. \& R.J. Johnston (eds.): Geography and the Urban Environment. Progress in Research and Applications, vol. VI, 1-27. John Wiley \& Sons, London.

Finch, Y.L. (1939). Geographical science and social geography. Annals of the Association of American Geographers 29, 1-28.

Fromkin, David (1981). The Independence of Nations. 171 pp. Praeger, New York.

Fromm, Erich (1962). Vaarallinen vapaus (Orig. Escape from Freedom, 1941). 264 pp. Kirjayhtymä, Helsinki.

Giddens, Anthony (1976). New Rules of Sociological Method: A Positive Critique of Interpretative Sociologies, 192 pp. Hutchinson, London.

Giddens, Anthony (1979). Central Problems in Social Theory: Action, Structure and Contradiction in Social Analysis. 249 pp. University of California Press, Berkeley.

Giddens, Anthony (1981). A Contempoiary Critique of Historical Materialism, vol. 1. 249 pp. MacMillan, London.

Giddens, Anthony (1984). The Constitution of Society. Outline of the Theory of Structuration. 402 pp. Polity Press, Cambridge.

Gilbert, E.W. (1960). The idea of the region. Geography $45,157-175$.

Gilbert, E.W. \& B. Litt (1960). Geography and regionalism. In Taylor, Griffith (ed.): Geography in the Twentieth Century. A Study of Growth. Field, Techniques, Aims and Trends, 345-371. Methuen, London.

Gore, Charles (1984). Regions in Question. Space, Development Theory and Regional Policy. 290 pp. Methuen, London.

Gottman, Jean (1973). The Significance of Territory. $169 \mathrm{pp}$. University Press of Virginia, Charlottesville.

Gottman, Jean (1982). The basic problems of political geography: the organization of space and the search for stability. Tijdschrift voor Economische en Sociale Geografie 73, 340-349.

Granö, Olavi (1978). Mitä aluemaantieteelle on tapahtunut? (What has happened to regional geography?, in Finnish). Terra 90, 165-168.

Granö, Olavi (1981). External influence and internal change in the development of geography. in Stoddart, D.R. (ed.): Geography, Ideology and Social Concern, 17-36. Basil Blackwell, Oxford.

Granö, Olavi (1982). Maisematutkimus maantieteen traditiona (Summary: Landscape studies as a geographical tradition). Terra 94, 7-12.

Gregory, Derek (1978). Ideology, Science and Human Geography. 198 pp. Hutchinson, London.

Gregory, Derek (1981a). Region. In Johnston, R.J. (ed.): The Dictionary of Human Geography, 284-285. Basil Blackwell, Oxford.

Gregory, Derek (1981b). Human agency and human geogiaphy. Transactions of the Institute of British Geographers, New Series 6, 1-18.

Gregory, Derek (1982a). Solid geometry: notes on the recovery of spatial structure. In Gould, Peter \& Gunnar Olsson (eds.): A Search for Common Ground, 187-219. Pion, London.

Gregory, Derek (1982b). A realist construction of the social. Transactions of the Institute of British Geographers, New Series 7, 254-256.

Gregory, Derek (1982c). Regional Transformation and Industrial Revolution. A Geography of the Yorkshire Woollen Industry. 294 pp. MacMillan, Hong Kong.

Gregory, Derek \& John Urry (eds. 1985). Social Relations and Spatial Structures. 440 pp. MacMillan, Hong Kong.

Grigg, David (1967). Regions, Models and Classes. In Chorley, Richard \& Peter Haggett (eds.): Models in Geography, 461-509. Methuen, London.

Guelke, Leonard (1975). On rethinking historical geography. Area 7, 135-139.

Guelke, Leonard (1982). Historical Understanding in Geography. An Idealist Approach. 109 pp. University Press, Cambridge.

Guelke, Leonard (1985). Unglorius isolation: Allan Pred's regional-historical geography. Annals of the Association of American Geographers 71, $131-132$.

Habermas, Jürgen (1979). Communication and the Evolution of Society. 239 pp. Heineman, London.

Habermas, Jürgen (1981). Theorie des kommunikativen Handelns, Band 2. 633 pp. Suhrkamp, Frankfurt am Main.

Halila, Aimo (1958). Suomen järjestötoiminnan piirijaon synnyn pääpiirteet (Referat: Hauptzüge in entstehender Kreiseinteilung der Organizationstätigkeit Finnlands). Historiallinen Arkisto $56,33-123$.

Hart, John Fraser (1982). The highest form of the geographer's art. Annals of the Association of American Geographers 72, 1-29.

Hartshorne, Richard (1939). The nature of geography: a critical survey of current thought in the light of past. Annals of the Association of American Geographers 29: 3-4.

Hartshorne, Richard (1959). Perspective on the Nature of Geography. 201 pp. Rand McNally, Chicago.

Harvey, David (1969). Explanation in Geography. 521 pp. Edward Arnold, London. 
Harvey, David (1970). Social processes and spatial form: an analysis of the conceptual problems of urban planning. In Jones, Emrys (ed. 1975): Readings in Social Geography, 288-306. Oxford University Press, London.

Hettner, Alfred (1927). Die Geographie, ihre Geschichte, ihr Wesen und ihre Methoden. 463 pp. Ferdinand Hirt, Breslau.

Hägerstrand, Torsten (1970). What about people in regional science? Papers of the Regional Science Association 24, 7-21.

Hägerstrand, Torsten (1973). The domain of human geography. In Chorley, Richard (ed.): Directions in Geography, 67-87. Methuen, London.

Hägerstrand, Torsten (1978). Survival and arena: on the life history of individuals in relation to their geographical environment. In Carlstein, Tommy, Parkes, Don \& Nigel Thrift (eds.): Timing Space and Spacing Time, vol.2., Human Activity and Time-Geography, 122-145. Edward Arnold, London.

Hägerstrand, Torsten (1982). Diorama, path and project. Tijdschrift voor Economische en Sociale Geografie 73, 323-339.

Jahoda, Gustav (1978). Cross-cultural perspectives. In Tajfel, $\mathrm{H}$ \& C. Fraser (eds.): Introducing Social Psychology, 76-95. Penguin Books, Harmonds worth.

James, Preston (1954). Introduction: the field of geography. In James, Preston \& Clarence Jones (eds.): American Geography, Inventory and Prospect, 3-18. Syracuse University Press.

James, Preston (1972). All Possible Worlds. A Hislory of Geographical Ideas. 622 pp. The Odyssey Press, New York.

Jeans, D.N. (1979). Some literary examples of humanistic descriptions of place. Australian Geographer 14, 27-32.

Jensen, Merrill (ed. 1952). Regionalism in America. $425 \mathrm{pp}$. University of Wisconsin Press, Richmond, Virginia.

Jones, Emrys (1975). Introduction. In Jones, Emrys (ed.): Readings in Social Geography, 1-12. Oxford University Press, London.

Jordan, Terry (1978). Perceptual regions in Texas. Geographical Review' 68, 293-307.

Kirk, William (1951). Historical geography and the concept of behavioural environment. Indian Geographical Journal, Silver Jubilee Edition $1951,152-160$.

Kirk, William (1963). Problems of geography. Geography 48, 357-371.

Knight, David (1982). Identity and territory: geographical perspective on nationalism and regionalism. Annals of the Associasion of American Geographers 72, 514-531.

Knight, David (1983). The dilemma of nations in al rigid state structured world. In Kliot, $\mathrm{N} \& \mathrm{~S}$. Waterman (eds.): Pluralism and Political Geography: People, Territoriality and State, 114137. Croom Helm, London.
Kostbade, J. Trenton (1965). A brief for regional geography. Journal of Geography 64, 362-366.

Kostbade, J. Trenton (1968). The regional concept and geographic education. Journal of Geography $67,6-12$.

Leach, Edmund (1970). Lévi-Strauss. 119 pp. Tammi, Helsinki.

Lee, Roger (1985). The future of the region: regional geography as education for transformation. In King, Russell (ed.): Geographical Futures, 77-91. Geographical Association. Sheffield.

Ley, David (1980). Geography without man: a humanistic critique. University of Oxford, School of Geography, Research Paper 24. 25 pp.

Ley, David (1981). Cultural/humanistic geography. Progress in Human Geography 5, 249-257.

Ley, David (1982). Rediscovering man's place. Transactions of the Institute of British Geographers, New Series 7, 248-253.

Liebkind, Karmela (1984). Minority identity and identification process: a social psychological study. Societas Scientiarum Fennica, Commentationes Scientiarum Socialium 22. Helsinki, $206 \mathrm{pp}$.

Lowenthal, David (1961). Geography, experience and imagination. Towards a geographical epistemology. Annals of the Association of American Geographers 51, 241-260.

Lukermann, Fred (1964). Geography as a formal intellectual discipline and the way in which it contributes to human knowledge. Canadian Geographer 8, 167-172.

Lönnqvist, Bo (1985). Identitet som kulturell resurs och manifestation. Nord-Nytt 26.

Martin, Bernice (1981). A Sociology of Contemporary Cultural Change. 272 pp. Basil Blackwell, Oxford.

May, J.A. (1970). Kant's Concept of Geography and its Relation to Recent Geographical Thought. $281 \mathrm{pp}$. University of Toronto Press, Toronto and Buffalo.

Mead, William R. (1981). A Historical Geography of Scandinavia. 313 pp. Academic Press. London.

Meinig, Donald W. (1972). American Wests, preface to a geographical interpretation. Annals of the Association of American Geographers 62, $159-184$

Meinig, Donald W. (1979). Symbolic landscapes. Some idealizations of American communities. In Meinig, Donald W. (ed.): The Interpretation of Ordinary Landscapes, 164-192. Oxford University Press, Oxford.

Morgan, F.W. (1939). Three aspects of regional consciousness. Sociologica! Review 31, 68-88.

Mårtenson, Solveig (1979). On the formation of biographies in scape-time environments. Lund Studies in Geography, Ser.B, Human Geography, No. 47. 191 pp.

Paasi, Anssi (1983). Maantieteen subjekti? Tie hu- 
manistisen ja behavioraalisen maantieteen nykytematiikkaan (Appendix: The subject of geography? The road to modern themes of humanistic and behavioural geography). University of toensuu, Publications of Social and Regional Sciences No. 34.333 pp.

Paasi, Anssi (1984a). Aluetietoisuus ja alueellinen identiteetti ihmisen spatiaalisen sidoksen osana (Summary: Regional consciousness and regional identity as part of man's spatial ties). Publications of the Society of Plamning Geography 13. Helsinki. 188 pp.

Paasi, Anssi (1984b). Suomen väliportaan aluejärjestelmän kehitys ja hahmottuminen suomalaisten aluetietoisuudessa (Summary: Development of the provincial division of Finland and its shape in the regional consciousness of Finnish people). Publications of the Society of Planning Geography 14. Helsinki. 151 pp.

Paasi, Anssi (1984c). Kansanluonnekäsitteestä ja sen käytöstä suomalaisissa maantiedon kouluoppikirjoissa - tutkimus alueellisista stereotypioista. (Summary: The concept of national character and its use in Finnish school geography textbooks - a study of regional stereotypes). University of Joensurt, Research Reports of the Faculty of Education No, 2. $136 \mathrm{pp}$.

Paasi, Anssi (1984d). Alueellinen identiteetti ja siihen vaikuttavat tekijät - esimerkkinä alueelljnen kirjallisuus (Summary: Regional identity and factors influencing on it - regional literature as one example). Terra 97, 113-120.

Paasi, Anssi (1984e). Den regionala identiteten och det samhälleliga medvetandet, iakttagelser frăn Finland. Nordisk Samhällsgeografisk Tidskrift $1,47-53$.

Pahl, R.E. (1965). Trends in social geography. In Chorley, Richard \& Peter Haggett (eds.): Frontiers in Geographical Teaching, 81-100. Methuen, London.

Parkes, Don \& Nigel Thrift (1980). Times, Spaces and Places: A Chronogeographic Perspective. $527 \mathrm{pp}$. John Wiley, New York.

Pocock, D \& R. Hudson (1978). Images of Uiban Environment. MacMillan, London. 181 pp.

Pred, Allan (1981a). Social reproduction and the time-geography of everyday life. Geografiska Annaler 65B, 5-22.

Pred, Allan (1981b). On paths and projects: individual behavios and its societal context. In Cox, Kevin \& Reginald Golledge (eds.): Problems in Behavioral Geography Revisited, 231-255. Methuen, London.

Pred, Allan (1981c). Power, everyday practice and the discipline of human geography. In Pred, Allan (ed.): Space and Time in Geography: Essays Dedicated to Torsten Hägerstrand, 30-55. Gleerup, Lund.

Pred, Allan (1981d). Production, family and freetime projects: a time geographic perspective on the individual and societal change in nineteenthcentury U.S. cities. Journal of Historical Geography 7, 3-36.

Pred, Allan (1983). Structuration and place: on the becoming of sense of place and structure of feeling. Journal for the Theory of Social Behaviour 13, 45-68.

Pred, Allan (1984a). Place as a historically contingent process: structuration and time-geography of becoming places. Amnals of the Association of American Geographers 74, 279297.

Pred, Allan (1984b). Structiration, biography formation and knowledge: observations on port growth during the late mercantile period. Society and Space 2, 251-275.

Pred, Allan (1985a). Comment in reply: unglorius isolation or unglorious mispres(s)entation? Annals of the Association of American Geographers $75,132-133$.

Pred, Allan (1985b). Power, practice, and consciousness: one's place in the world and the world in one's place. Paper presented at a seminar marking Torsten Hägerstrand's receipt of an Honorary Doctorate from the Ohio State University, Columbus, Ohio, June 13, 1985.

Pred, Allan (1985c). The social becomes the spatial, the spatial becomes the social: enclosures, social change and the becoming of places in Skåne. In Gregory, Derek \& John Urry (eds.); Social Relations and Spatial Structures, 337-365. MacMillan, Hong Kong.

Regiona! identitet och förändring i den regionala samverkans samhälle (1978). Acta Universitatis Uppsaliensis $11.143 \mathrm{pp}$.

Relph, Edward (1976). Place and Placelessness. 156 pp. Pion, London.

Robinson, G.W.S. (1953). The geographical region: form and function. Scottish Geographical Magazine 69, 49-58.

Ross, R.N. (1975). Ellipsis and the structure of expectation. San Jose State Occasional Papers in Linquistics 1, 183-191.

Rykiel, Zbigniew (1985). Regional consciousness in the Katowice region, Poland. Area 17, 285-293.

Saarinen, Thomas F. (1976). Envirommental Planning, Perception and Behavior. $262 \mathrm{pp}$. Houghton Mifflin, Boston.

Sack, Robert D. (1983). Human territoriality: a theory. Annals of the Association of American Geographers 73, 55-74.

Samuels, Marwyn (1971). Science and geography: an existential appraisal. Unpublished Ph.D. thesis, University of Washington. $285 \mathrm{pp}$.

Sauer, Carl O. (1925). The morphology of landscape. In Leighly, John (ed. 1963): Land and Life: A Selection from the Writings of Carl Ortwin Satter, 315-350. University of California Press, Berkeley and LA

Sauer, Carl O. (1941). Foreword to historical geography. In Leighly, John (ed. 1963): Land and 
Life. A Selection from the Writings of Carl Ortwin Sauer, 351-379. University of California Press, Berkeley and LA.

Sayer, Andrew (1979). Epistemology and conceptions of people and nature in geography. Geoforum 10, 19-44.

Sayer, Andrew (1984). Method in Social Science. A Realist Approach. 271 pp. Hutchinson, London.

Sayer, Andrew (1985). The difference that space makes. In Gregory, Derek \& John Urry (eds.): Social Relations and Spatial Structures, 49-66. MacMillan, Hong Kong.

Schultz, Hans-Dietrich (1980). Die deutschsprachige Geographie von 1800 bis 1970 . Ein Beitrag zur Geschichte ihrer Methodologie. Abhandlungen des geographischen Instituts, Anthropogeographie 29. Berlin. 478 pp.

Seamon, David (1979). A Geography of Lifeworld. 227 pp. Croom Helm, London.

Shortridge, James (1984). The emergence of 'Middle West' as an American regional label. Annals of the Association of American Geographers $74,209-220$.

Shortridge, James (1985). The vernacular Middle West. Annals of the Association of American Geographers 75, 48-57.

Smart, Ninian (1983). Worldviews: Crosscultural Explorations of Human Beliefs. $190 \mathrm{pp}$. Scribner's, New York.

Smith, C.T. (1965). Historical geography: current trends and prospects. In Chorley, Richard \& Peter Haggett (eds.): Frontiers in Geographical Teaching, 118-143. Methuen, London.

Soja, Edward (1971). The political organization of space. Association of American Geographers, Commission on College Geography, Resource Paper No. 8. 54 pp.

Soja, Edward (1980). The socio-spatial dialectic. Annals of the Association of American Geographers 70, 207-225.

Soja, Edward (1985a). Regions in context: spatiality, periodicity, and the historical geography of the regional question. Society and Space 3, 175 -190 .

Soja, Edward (1985b). The spatiality of social life: towards a transformative retheorisation. In Gregory, Derek \& John Urry (eds.): Social Relations and Spatial Structures, 90-127. MacMillan, Hong Kong.

Tannen, Deborah (1979). What's in a frame? Surface evidence for underlying expectations. In Freedle, Roy (ed.): New Directions in Discourse Processing, 137-181. Norwood, New Jersey.

Thrift, Nigel (1983). On the determination of social action in space and time. Society and Space $1,23-57$

Thrift, Nigel \& Allan Pred (1981). Time-geography: a new beginning. Progress in Human Geography 5, 277-286.

Tuan, Yi-Fu (1975). Place: an experiental perspective. Geographical Review 65, 151-165.

Tuan, Yi-Fu (1976). Humanistic geography. Annals of the Association of American Geographers $66,266-276$.

Tuan, Yi-Fu (1977). Space and Place: The Perspective of Experience. 235 pp. Edward Arnold, London.

Tuan, Yi-Fu (1978). Space, time, place: a humanistic frame. In Carlstein, Tommy, Parkes, Don \& Nigel Thrift (eds.): Making Sense of Time, 716. Edward Arnold, London.

Urry, John (1981). Localities, regions and social class. International Journal of Urban and Regional Research 5, 455-474.

Urry, John (1983). Some notes on realism and the analysis of space. International Journal of Urban and Regional Research 7, 122-127.

Urry, John (1985). Social relations, space and time. In Gregory, Derek \& John Urry (eds.): Social Relations and Spatial Structures, 20-48. MacMillan, Hong Kong.

Wahlström, Lage (1984). Geografiutveckling och geografins utveckling... som om platser betydde något. Meddelanden från Göteborgs Universitets Geografiska Institutionen, ser.B, Nr.76. 232 pp.

Watson, James (1971). Geography and image regions. Geographica Helverica Heft 26, 31-33.

Whittlesey, Derwent (1954). The regional concept and the regional method. In James, Preston \& Clarence Jones (eds.): American Geography, Inventory \& Prospect, 19-68. Syracuse University Press.

Williams, Colin \& Anthony Smith (1983). The national construction of social space. Progress in Human Geography 7: 4.

Williams, Raymond (1961). The Long Revolution. 370 pp. Chatto \& Windus, London.

Wright, J.K. (1947). Terrae incognitae: the place of the imagination in geography. Annals of the Association of American Geographers 37, 115.

Wörner, Rolf (1938). Das geographische Ganzheits Problem vom Standpunkt der Psychologie aus. Geographische Zeitschrift 14, 340-344.

Zelinsky, Wilbur (1980). North America's vernacular regions. Annals of the Association of American Geographers 70, 1-16. 